\title{
ANÁlisis del CONCEPTO PLURALIDAd Y AUTONOMÍA DE LA VOLUNTAD EN EL CONTRATO SOCIETARIO
}

\section{INTRODUCCIÓN}

La sociedad por acciones simplificadas (desde ahora SAS) ha generado una multiplicidad de asociaciones después de su expedición con la Ley 1258 de 2008. Ello ha permitido la simplificación de los trámites y las dinámicas para registrarse como nuevos empresarios que se van constituyendo. El espíritu de las SAS, es la generación de nuevas empresas y esto fomenta el crecimiento económico, la inversión extranjera y la constitución de sociedades que fomenten la modernización del Estado y los procesos de trámite que mucho dolor de cabeza le han generado a las personas naturales que habían querido conformar otro tipo de sociedad comercial, por ahorrase unos cuantos tramites.

Este trabajo de investigación tiene como objetivo mirar dentro del proceso de conformación y desarrollo interno de las SAS, el concepto de autonomía entre los accionistas que entran en la conformación de este tipo de sociedades. Quien asume los riesgos, cuales son los procesos de responsabilidad cuando se establecen los estatutos que después se registran ante la Cámara de Comercio. Preguntas como la disolución de 
la sociedad y la autonomía que tienen los miembros para considerar los riesgos y las pautas de conducta y las contravenciones que se puedan presentar en cada uno de ellos hacen necesario la discusión sobre los procesos de autonomía entre los sociosaccionistas que entran a configurar la sociedad por acción simplificada.

La gran mayoría de la literatura revisada como los textos guías del Doctor Francisco Reyes Villamizar, José Ignacio Narváez con sus investigaciones sobre la teoría general de las sociedades, nos lleva a pensar que el tema de la autonomía y la pluralidad desde la perspectiva epistemológica y la filosofía del derecho comercial, se convierten en categorías fundamentales en el proceso de construcción del conocimiento sobre las Sociedades por Acción Simplificada para el país, pues muchas veces en una sociedad de inversionistas, el liderazgo y la suma de los factores subjetivos que son inherentes a la naturaleza humana, como la envidia, el temor al riesgo, la seguridad personal o simplemente la incompatibilidad para trabajar de manera conjunta, no están estipulados en la constitución de este tipo de sociedades. Este trabajo de investigación busca la revisión de los conocimientos en el funcionamiento de las Sociedad (SAS) en el tema de la autonomía y la pluralidad, pues esta estructura de la Sociedad SAS, implica la reducción de la junta directiva, los miembros que hacen parte de ella y las cargas económicas obligatorias que son innecesarias para el avance de las empresas que se forman bajo esta figura.

Las Cámaras de Comercio registran el exponencial crecimiento de las SAS como alternativa económica (Cámara de Comercio de Cartagena) ágil, a su vez según la literatura y los resultados de las investigaciones en Derecho comercial revisadas para la elaboración de esta tesis de Maestría es que la conformación de las sociedad SAS, es mucho más segura que las Sociedades Limitadas, las Sociedades en comandita bajo en régimen de responsabilidad y las iniciativas realizadas por personas naturales. Las investigaciones sobre este tipo de sociedades es diversa y nos lleva a caminos de 
discusión bastante significativos. Pero en este caso sólo analizaremos en concepto de autonomía y pluralidad que se puede encontrar en este tipo de conformación de sociedades. La exposición de motivos para llevar a cabo una investigación de corte epistemológica, es que se habla de la conformación de la SAS pero no de los elementos que están presentes en el lenguaje de su configuración. Es decir, que el núcleo central, como lo dice el epistemólogo húngaro Irme Lakatos en su metodología de los programas de investigación establece que para la entender un fenómeno como objeto de estudio de investigación, se debe analizar el núcleo firme de la propuesta para poder desde allí entender la naturaleza de lo que se quiere analizar en su constitución más amplia. Es así que para entender el espíritu de la conformación de las Sociedades Generalmente se deben comprender los conceptos y categorías de análisis que estructuran la misma. Para eso revisaremos la autonomía como categoría principal de nuestro trabajo, acompañada del concepto de pluralidad como elementos esenciales para comprender los fundamentos de esta nueva forma de conformación de sociedades comerciales que está creciendo de forma muy rápida en el país.

La metodología aplicada en esta investigación, tiene tres etapas de elaboración de la tesis. En primera instancia se realizó un estado del saber que permite tener un conocimiento amplio de la literatura internacional y nacional sobre el discurso jurídico y político del alcance y las limitaciones que ha tenido para los países la implementación de las sociedades SAS. El estado del arte nos ha arrojado las ventajas administrativas que acarrea la realización de la sociedad SAS, también se analizan los costos que se ahorran los inversores en trámites de legalización. A su vez las investigaciones se encaminan a la formas cómo las sociedades SAS promueven la inversión interna de pequeños y micro empresarios abaratando costos de personal, de la junta directiva y de los trámites de legalización ante la Notarias y Cámara de Comercios, pero no se ha encontrado bibliografía que revise temas o núcleos problémicos sobre la naturaleza de los conceptos que se dinamizan alrededor de las sociedades SAS cuando son conformada por una sola persona. 
El concepto de autonomía se ha revisado acá como una categoría fundamental, pues permite evidenciar los alcances subjetivos en la construcción de la sociedad. Es decir, el concepto de autonomía nos lleva a la pregunta por ¿En una sociedad de inversores quien toma las decisiones, quien pone las reglas de juego? ¿Cuáles son los criterios para ser parte de la Sociedad SAS y cuáles son las limitaciones y ventajas? ¿Desde el punto de vista del poder, quien decide la salida de un inversor dentro de la sociedad? Estas son preguntas que revelan las dinámicas internas de la Sociedad que desde la construcción de conocimientos se deben valorar para tener una visión interna de los retos, alcances y debilidades de la conformación de las SAS como una alternativa comercial que apunta al desarrollo empresarial del país cuando se piensa en constituir por una sola persona.

Por otra parte, el concepto de pluralidad permite conocer las relaciones dentro la sociedad SAS, pues ayuda a desarrollar preguntas sobre la conformación de la sociedad con un solo inversor o socio, las obligaciones adquiridas dentro de la sociedad y las relaciones legales y normativas adquiridas motivadas por las diferencias de criterios, metas, objetivos que establezca cada una de las personas que hacen parte de la sociedad. Es así como el concepto de pluralidad es una herramienta para entender las diversidades de intereses al interior de la sociedad, como dirimir los conflictos, como desarrollar elementos de cohesión donde se presentan diferencias de intereses para conformar la sociedad.

En síntesis, esta investigación de tesis de maestría, busca hacer una reflexión sobre el concepto de pluralidad y autonomía dentro de las sociedades SAS, para dar a la comunidad académica y a los empresarios y pequeños emprendedores una herramientas teóricas para conocer las dinámicas internas de la conformación de estas sociedades, que después de la puesta en marcha según la Ley1258 de 2008, se han multiplicado de manera sustancial en los últimos 5 años de vigencia. La tesis está estructurada en dos 
(2) capítulos, una conclusión y las referencias bibliográficas. En el primer capítulo se desarrolla la metodología del trabajo, se evidencia la búsqueda de información y la forma como se ha llegado y abordado la temática. Se discute como se abordan en concreto dentro de una tesis de derecho y la importancia de la epistemología en la formación de los conceptos.

El primer capítulo de la tesis versa sobre el desarrollo de los conceptos de pluralidad, las teorías que lo gobiernan y autonomía dentro del contrato de las sociedades y de igual manera por las sociedades por acciones simplificadas, acá se pretende hacer un acercamiento entre las concepciones de pluralidad y autonomía para poder tener una visión interna del objeto de estudio que ayuden al desarrollo de los conocimientos sobre las sociedades en general y por su puesto las SAS, analizándolas desde su interior, sus elementos subjetivos y las percepciones que se desarrollan al interior del objeto que estamos estudiando. Por último y segundo capítulo se realizará un análisis del contexto autonomía de la voluntad en el contrato societario y una breve reflexión sobre la naturaleza de las sociedades por acciones simplificadas y los avances que ha tenido en la literatura del Derecho Comercial.

La tesis es un ejercicio de pensar diferente dentro del tema de la SAS, pues la revisión de la literatura nos lleva a la forma más no se ha preguntado por el espíritu y la naturaleza de las sociedades. Se espera que este documento sea una apertura a nuevas investigaciones desde la filosofía del derecho y la epistemología que le permita a los estudiantes conocer los fundamentos para poder desde allí generar nuevos conocimientos. Debido a la debilidad de las fuentes bibliográficas en materia de producción de saberes sobre el análisis de los conceptos nos hemos centrado en la preparación de nuestras percepciones y en la formulación de un marco teórico que ayude a la ampliación de los conocimientos. 
Quiero agradecer a mi tutor de tesis Dr. Javier González, por el apoyo para emprender una tarea ardua dentro del derecho que es desentrañar su filosofía y sus concepciones, el empuje por la tarea filosófica es importante para que las nuevas generaciones de abogados se formen bajo los paradigmas explicativos y las metodologías de investigación que permitan la construcción de hipótesis progresivas dentro de esta rama fundamental que es el derecho comercial. La investigación es un factor de desarrollo social y cambio y el derecho debe apostar a la producción de nuevos conocimientos empleando los tipos de métodos de análisis para la constitución de conocimientos que permitan el avance en los temas que más atañen a esta rama del derecho como lo es el derecho comercial. Investigar significa llevar a cabo un proceso para la búsqueda de un conocimiento elevado y complejo que podamos llamar científico, es así como discutir sobre conceptos y hacer apreciaciones sobre ellos de una práctica jurídica, una Ley y una nueva dinámica comercial, es un punto de arranque para la iniciativa de nuevas investigaciones en el área. 


\section{CAPITULO 1.}

\section{ANTECEDENTES FILOSÓFICOS Y EPISTEMOLÓGICOS DE LA PLURALIDAD}

Desde los inicios del desarrollo de la humanidad, el hombre o individuo ha necesitado de la affectio societatis o animus societattis, (Arbelar. 2000. Pg. 30.) es decir, la intención o el propósito de participar en sociedad, que es más claro o evidente las llamadas en participar en sociedades de personas, porque en ellas el individuo desempeña un papel determinante y decisivo en la persona de los asociados, su nombre, su pensamiento y demás características personales, su conocimiento y su moral en que ellos converjan. (Baena. 1984, p.15). No es normal que personas extrañan se asocien; por lo general las sociedades se hacen entre amigos, colegas, conocidos o alguna manifestación interna o intrínseca y externa los vincula. (Calvo, 2012. p .402).

Conviene siempre conocer la historia de toda ciencia y por qué no la génesis de los conceptos, pero la importancia del conocimiento histórico, se revela especialmente en la disciplina filosófica: ya que en éstas, el presente no se entiende sin tener en cuenta el pasado. En ella el pasado revive en el presente. Los problemas filosóficos hoy discutidos como los conceptos de pluralidad y autonomía son esencialmente en los temas contractuales, los mismos que se presentaron en años anteriores pensadores de la antigüedad. (lakatos. 1956.p. 232). 
El examen de los sistemas filosóficos se ofrecen como una especie de experimento lógico donde podemos ver bien pronto que conclusiones se obtienen partiendo de ciertas premisas: y podemos sacar partidos de ello para poder llegar a un sistema más perfecto, evitando los errores cometidos y aprovechando los progresos ya realizados. (Rosmini. 1823. P.245.)

La filosofía es un medio de estudio y de investigación que nos ayuda en nuestras tareas, nos ofrece un cúmulo de observaciones, razonamientos, de distinción, que no podía realizar un solo individuo; como tampoco un solo artífice podría actuar el mismo EXNOVO todos los instrumentos de su arte.

En la historia de la filosofía del derecho muestra especialmente que en todo tiempo sea meditados sobre el problema del derecho, la justicia y la interpretación: problema que, por lo tanto, no fue inventado artificiosamente, sino que responde a una necesidad natural y constante del espíritu humano como es el de asociarse. (Recasens. 1946.p. 31).

Pero desde el punto de vista filosófico y epistemológico como sub disciplina del Derecho no se presentan como autónoma los conceptos de pluralidad, autonomía y sociedad, si no mezclada con la teología, sociología, moral y la política esta ultima el gran pensador Aristóteles, manifiesta una interpretación y crecimiento del Estado desde el individuo manifestando su inicio desde la Familia, la tribu, la aldea, la ciudad o polis (Los grados intermedios) (Del Vecchio, pg.14).

Prevaleciendo un espíritu observador de Aristóteles por encima del quien fue su maestro PLATON quien en su razonamiento era más especulativo. Agrega el pensador 
ARISTOTELES que la sociedad es establecida perpetuamente por la familia. Y el Individuo, para no necesitar de la sociedad, debería ser algo más, o algo menos que un hombre: esto es, un bruto o un Dios. (Del Vecchiopg, 15.).

Desde allí surgen las teorías contrato social (Rousseau), la teoría del contrato de asociación, independientemente del político como lo desarrollo (Suárez), este pensamiento de los contratos fue aceptado por casi todos los pensadores de la edad moderna.

Mirando cada uno de los conceptos desde el punto de vista sociológico, histórico y político. Desde un punto de vista patrimonial o económico, también ha sido una necesidad humana la de asociarse para desarrollar más eficazmente unas serie de actividades que en la práctica constituye un imposible para el comerciante individual. (Pinzon.1984.p.14 y15).

En la época del imperio romano se comenzó a preciar las primeras formas asociativas de contenido mercantil, su origen más remoto se encuentra en la conservación del patrimonio familiar que aunamos al de un extraño se llegó a la utilización de explotación de mina o recaudo de impuestos. (Arbelar, 2000, P.28.).

Con el desarrollo del comercio en roma se llevó en las instituciones un grado de perfeccionamiento que aun hoy las conservamos casi auténticas. Un ejemplo de ello son las Ligas Hanseaticas, estuvo compuesto de comerciantes, donde surgieron muchas corporaciones, luego las Ordenanzas De Bilbao, estas especies de codificación tuvo vigencia en España y sus colonias; luego en Marzo de 1673 se expide en Francia La Ordenanza Del Comercio, que en ocho años después se convirtió en el Código de 
Napoleón que fue utilizado en cada una de la expansiones políticas que tubo Francia y sus conquistas territoriales. (Navarra. 2006, p. 10)

\subsection{LAS TEORÍAS APLICABLES AL DERECHO DE ASOCIACIÓN}

La sociedad data como una institución que nace desde las primeras concepciones del derecho romano y muestra un rastreo de la institucionabilidad de la Persona jurídica, (Ferrara, 1929.p.22) lo cual define que es la aptitud de ser sujeto de derecho, pero esta la tiene el ser humano, que esos derechos las pueden tener una colectividad de ellos que se unen para tener un fin común que se puede denominar persona jurídica.

Desde antaño los comportamientos y hechos de los seres humanos han demostrado su sociabilidad por su naturaleza "un animal político" como dijera Aristóteles: "Cum appetitu societatis" y al decir Grocio el hombre busca la cooperación de sus semejantes, aúna esfuerzos y sus bienes para tratar de alcanzar la meta que se propone.(Gómez, 1998.p. 83).

Pero es insuficiente el ánimos de asociación entre los seres humanos se requeriría del derecho objetivo, es decir un reconocimiento de una autoridad. "El reconocimiento, como dice FERRARA, produce la personalidad la investidura del ser humano como son los atributos de la personalidad que unitariamente lo obtienen las personas, que imprime esa connotación jurídica a las organizaciones sociales y es el efecto nuevo, que antes no existía y que las partes eran por si sola imponentes para producir"; y agrega el mismo autor: "las personas jurídicas solo en el derecho y por el derecho faltando el re cocimiento no hay más que colectividades de individuos". Aunque sobre este punto son 
muchas las doctrinas existen dos teorías principales: la de la ficción y la de la realidad. (Ferrara, 1929. p. 125.).

Teoría De La Ficción: La formulo Savigny en su obra de derecho romano y la sintetiza así FRANCESCO FERRARA: Todo derecho existe a causa de la libertad ingénita de cada hombre. Por esto, el concepto primitivo de persona debe coincidir con el hombre y esta identidad de dos conceptos se puede expresar en fórmula: todo hombre singular y solo hombre singular es capaz de derechos. Pero el derecho positivo puede modificar este principio, o negando la capacidad de algunos hombres, como sucedió con algunos esclavos, o extendiéndola a entes, que son hombres, como sucede en las personas jurídicas. La capacidad jurídica puede ser extendida a sujetos artificiales creados por simple ficción. (Narváez. 2002. P.43-44).

Esta teoría fue acogida por nuestra legislación civil, por el código civil de Andrés Bello y este autor se inspiró en el código francés y en SAVIGNY.

Teoría De La Realidad: Para los seguidores de esta tesis, la personalidad jurídica de los entes colectivos es una realidad. La colectividad está hecha a semej anza e imagen del hombre con voluntad propia, o sea distinta de las de los hombres que la componen y no hay que impida o haga imposible concebir derechos que pertenezcan a otros seres que no sean seres humanos, para concluir que la "sola finalidad colectiva concede la personalidad, en el mismo acto en que se hizo buscar ese fin y que, por consiguiente, no es necesaria la intervención del legislador”. (Narváez. 2002. P.42.)

Sin embargo, así como el Estado interviene para reconocer personalidad ante la ley, es decir, para que cobre realidad ante el mismo estado la existencia de la persona 
humana, es lógico también que se reconozca la de ese ser colectivo, que se sepa su existencia, mediante un registro: Nacimiento de la persona humana (registro civil); nacimiento de la persona jurídica (inscripción Estatal).

Con la finalidad de llegar a la institución de las sociedades, ha existido dos aspectos descollantes o fundamentales en toda sociedad, como suele llamarlo José Ignacio Narváez: uno el CONTRACTUAL que se refiere a su origen, y el ORGANIZATIVO mediante el cual los distintos órganos sociales desempeñan sus funciones coordinan las múltiples relaciones internas y externas.

Sobre las tesis de la creación y funcionamiento de la sociedad se han planteado diversas doctrinas de las cuales sobresalen la contractualita clásica, la del acto unilateral, la del acto colectivo, la del acto complejo, la de la institución y la del contrato plurilateral de organización.

Teoría Contractualita Clásica: Se fundamenta en la noción de contrato que estructuraron los jurisconsultos romanos, por consiguientes establecieron que la sociedad se concibe como un acto voluntario en el cual se estipula obligaciones y derechos recíprocos lo cual genera un intercambio de prestaciones, sin embargo el acuerdo de voluntades del cual nace la sociedad los contratantes tienen interés comunes y no contrapuestos. Esta es la teoría que adopta la legislación colombiana en sus artículos 98 y 864 del Código de Comercio Colombiano.(Peña Nossa, 2011.p.19.). (Narváez, 2002. P. 39-40). La teoría del acto o del negocio jurídico constituye el pilar fundamental del Régimen legal de toda sociedad, a partir de su definición universal como un contrato, desde su concepción romana y las definiciones del código décimo canónico (art. 1832 del Código Civil Francés que manifiesta que la sociedad "es un contrato"). 
Teoría Del Acto Unilateral: Hasta mediados del siglo XIX la doctrina tradicional distinguía entre actos unilaterales y actos plurilaterales, tomando como base el hecho de unas o varias declaraciones de voluntades donde el contrato era el único ejemplo de acto plurilateral, pero en la segunda mitad de esa centuria empezó a criticarse en ALEMANIA la insuficiencia de la noción contractualita clásica, donde se observó en las corporaciones que existía varios negocios jurídicos, sin que ostente las características de los contratos, se afirmó que los actos corporativos son configurado por un acto jurídico- social unilateral o por un acto colectivo.

Teoría Del Acto Colectivo: Esta fue la réplica de la teoría anterior se afirmó que la sociedad es un acto pluripersonal en que las declaraciones de voluntad tienen el mismo contenido no se entrecruzan o cambian entre sí, no que son paralelas, es decir estos no, actúan uno frente al otro u otros, sino cada uno al lado de los demás consocios, ya que no están en contraposición, sino yuxtapuesto para buscar un fin común. (Garrigues, 1987. P.26.).

Teoría Del Acto Complejo: Según algunos juristas alemanes esta fue otra respuesta al enfoque del acto constitutivo simple o unilateral. Afirma que las voluntades individuales de los asociados o interdependiente y actúan colectivamente para fundirse en una voluntad unitaria por ejemplo: las decisiones de junta de socios o Asamblea general de socios, Etc. (Garrigues, 1987. P.27-28.).

Teoría De La Institución: Como afirman los doctrinantes MAURICE HAURIOU Y GEOGE RENARD la existencia de grupo sociales intermedios entre el individuo y el estado que llegan a ser sujetos de derecho, entre esos "seres sociales" están (la familia, la iglesia, los sindicatos, las sociedades, etc., de manera fáctica que tienen una vida independiente de sus miembros o integrantes. De esta realidad surge un 
régimen para la actuación del ser social, tal como acontece con los estatutos de las sociedades. Además tales "seres sociales" ostentas tres características, a saber. a) Una Idea directriz (causa final), que se manifiesta en distintos órganos destinado a un fin común; b) el principio de autoridad encausado en cumplir la idea directriz (causa final) y c) la comunión de todos sus miembros alrededor de la idea directriz y de su realización. HAURIOU sostuvo, además, que toda asociación es un fenómeno a la vez individual y social : individual por que se realiza en forma de una convención en la participación individuos que hacen aportes de recursos; y social, porque el contrato funda una voluntad común, que da nacimiento a "una institución corporativa cuya existencia de hecho reclama la personalidad jurídica"; es decir esa institución tiene los atributos propios de la persona: nombre, capacidad jurídica, domicilio, patrimonio y nacionalidad.

Pero fue EMILIO GAILLARD quien desarrolló la teoría de la institucional (Narváez. 2002. P. 43-44) sobre estos supuestos: 1) del contrato nace una institución cuya finalidad es un interés de intermediación entre los individuos y los estados; 2) la sociedad es un sujeto de derechos, por cuanto tiene un interés legítimo de sus socios; 3 ) la sociedad lleva implícita una autoridad en la búsqueda del fin que la institución debe cumplir, autoridad que proviene de la comunión de fuerzas comprometidas en la sociedad; 4) El poder es atribuido en vista del interés social y no se reparte en forma igualitaria sino proporcionalmente a los servicios rendidos a dicho interés; 5) la institución cuenta con órganos para realizar cada función; 6) existe continuidad en la gestión, por cuanto la institución implícitamente presupone un interés perdurable y no entiende a una sola operación; las cláusulas estatutarias son simples medios para la consecución del interés social, de ahí que puedan ser modificadas si son necesarias.

Teoría Del Contrato Plurilateral De Organización: TULIO ASCARELLI afirma: "la sociedad nace de un contrato, más precisamente de una sub-especie de 
contrato que podemos llamar PLURILATERAL. las diversas peculiaridades de la constitución se concilian con el concepto fundamental de contratos( pues existe en la sociedad un contraste de interés que el contrato tiende a resolver, diversamente de lo que ocurre en la hipótesis del acto complejo), no obstante evidenciar la existencia de una subespecie particular: la del contrato plurilateral Cuyas características aparecen en el proceso de constitución, en la regla de que el vicio de una adhesión no vicia el contrato entero, etc.)" y en el Código Civil italiano de 1942 acogió la designación de CONTRATO PLURILATERAL que es el sustrato de la persona jurídica; a través de esta, las distintas relaciones jurídicas se conciben y se relacionan unilateralmente. A las relaciones de cada parte con "todas las demás”, suceden las de cada parte con la persona jurídica; a las relaciones de "toda las partes" frente a los terceros, las persona jurídica con los terceros". (Reyes Villamizar, 2004. P. 87-88).

El contrato de sociedad es plurilateral por que pueden intervenir dos o más personas, (Ferrara, pg. 153) de modo que cada contraste tiene frente a sí, simultáneamente, tantas partes cuantos asociados sean, y sin alterar la sustancia, permite la adhesión de nuevos socios y el derecho de receso, o sea la salida de los existentes. Así lo define el Código Civil Colombiano en su Art 1495 "el contrato o convención... y el Código de Comercio Colombiano o Decreto 410 de 1971, en su artículo 864 "El contrato es un acuerdo de dos o más partes para constituir, regular o extinguir entre ellas una relación jurídica patrimonial, y salvo estipulación en contrario".(Narváez. 2002. P. 46. )

Pero, en lo que respecta al contrato societario la legislación mercantil trae consigo en la definición del artículo 98 c.co. Los elementos esenciales del contrato de sociedad "El contrato de sociedad dos o más personas se obligan a hacer un aporte en dinero, en trabajo o en otros bienes apreciables en dinero, con el fin de repartirse entre sí las utilidades obtenidas en la empresa o actividad social”. (Espinosa. 2008. P.127.). 
La sociedad, una vez constituida legalmente, forma una persona jurídica distinta de los socios individualmente considerados." Con esta definición podemos resaltar unos supuestos o elementos esenciales: 1) Dos o más personas, (pluralidad) con lo que descarta la denominada "sociedad con solo socio o sociedad unipersonal". 2) La obligación de dar un aporte; 3) el beneficio común; 4) La utilidad social y 5) El affectiosocietatis; que toda sociedad mercantil debe llevar consigo, sin embargo, en Colombia a pesar de llevar una costumbre o tradición de ser un derecho formal y solemne han venido trayendo a medida que encuentran unas tendencias modernas o mejor dicho pensamientos europeos y de los estados unidos para implantar un nuevo sistema mal denominado sociedad unipersonal o sociedad anónima simplificada, a través de la ley 1258 de 2008, que define en su Artículo 1 o la sociedad por acciones simplificadas pueden ser constituidas por una o varias personas naturales o jurídicas, quienes sólo serán responsables hasta el monto de sus aportes.

En virtud a lo anteriormente expuesto, la PLURALDAD DE SOCIOS, como dice el maestro ANTONIO ROCHA quien sostenía que el vocablo asociado o genérico, comprensivo del término socio-propio de los titulares de parte de interés o de cuotasasí como del accionista que corresponde a quien invierte en la sociedades por acciones. Como la sociedad nace de un contrato al cual se mantiene aferrada, siempre presupone la conjunción de voluntades de por lo menos dos personas, pues no es concebible el acuerdo consigo mismo. Sin esa pluralidad no hay AFFECTIO SOCIETATIAS, ni sumatorias de aportes ni partición proporcional en las ganancias. (Rocha, 1963. P.10).

1.1.1. El desarrollo del concepto "sociedad" en el contrato. Los precursores de las tendencias institucionalistas del derecho de sociedades sostuvieron que la sociedad es una institución, con voluntad y personalidad jurídica propias y que su objeto social se encuentra por encima de los intereses privados de cada uno de los 
socios, y son precisamente estas circunstancias las que determinan los límites a la autonomía de la voluntad privada. (Vanasco. 2006. P. 10).

Aquí se establece el principio de autonomía cuando los socios establecen las formas por las cuales debe ser configurado el documento de conformación de la sociedad y la forma de realización. Son varias las consecuencias que se derivan de una interpretación institucionalista del derecho de sociedades, dentro de ellas podemos mencionar que la ley tiene una función directiva que se deriva de su carácter imperativo, que por cierto la doctrina y la jurisprudencia establecerán su criterio en la intención del legislador, y no en la voluntad de las partes que es lo que se quiere que se aplique siempre en estos casos.

La autonomía privada en materia societaria, en especial en el tema de la sociedad anónima, no es un don natural de los contratantes sino una concesión estatal, que es motivada por hacer más exigentes los controles gubernamentales, entre otras cosas como consecuencia de considerar que los arreglos de las partes tienden a perjudicar a quienes los ejercen.

Es así como se asimila la sociedad anónima al Estado y el accionista al ciudadano, por lo tanto, los derechos de este último son irrenunciables; La tipicidad del derecho de sociedades está hecha para salvaguardar el interés general, como quiera que las fuerzas del mercado son de por sí desequilibrantes y vulneradoras del interés común. De allí entran en contradicción los conceptos que estamos debatiendo como lo son la autonomía y la pluralidad de socios en el contrato, pues muchas veces los interés particulares por lo cual se monta la sociedad y se cimienta el contrato, terminan en una desigualdad de poderes que se diluyen bajo el concepto de autonomía. En consecuencia, no pueden existir sociedades atípicas ni implementarse conceptos que se aparten de los 
parámetros señalados por el legislador, así que discutir sobre el concepto de la autonomía que está registrado en este tipo de sociedades donde hay una pluralidad de socios es donde se puede generar el mejor terreno para la el desarrollo de la discusión.

El concepto de autonomía ha venido evolucionando en los procesos de entender las relaciones y las dinámicas internas dentro del contrato societario, pero las discusiones sobre el poder y las relaciones que se tejen alrededor de ellas a partir de la diversidad de socios es lo que se pone en duda al momento de revisar las ideas filosóficas y epistemológicas de los procesos del contrato societario. Como primera medida, donde existe una pluralidad de socios hay una diversidad de intereses que no pueden entrar en un proceso de igualdad y mucho menos de equidad, como el capital financiero es lo que gobierna el espirito de la sociedad, la pluralidad se convierte en un obstáculo epistémico que protege de alguna manera la reproducción excesiva de las relaciones de poder. La voluntad contractual dentro de las sociedades SAS está regulada por finas estrategias de poder que se esconden bajo el concepto de la autonomía de los socios. Como la Ley prevé estos movimientos al interior de la conformación de las sociedades y es totalmente legal y legítimo en el contrato societario, es un llamado de atención en esta tesis de maestría que si no se discute sobre los alcances éticos de los poderes al interior de la conformación de las sociedades, los desbalances de poder podrían convertir a las SAS en un ejercicio de perdida de libertades comerciales y se estarían desprotegiendo a los pluralidad de socios que en el ámbito accionario tienen menos ventaja competitiva en relación a los que mayor adquisición accionaria están invirtiendo en la sociedad. La discusión sobre la autonomía y la pluralidad de socios, es importante para el ejercicio del derecho comercial y los derechos individuales de los sujetos que intervienen en ese proceso. Por ejemplo Wilson Ivan Morgentein de la Universidad Santo Tomas, llama la atención de estos elementos, así que la discusión de los conceptos en el contexto del contrato societario es de suma importancia para el desarrollo de las sociedades SAS en Colombia. 


\subsection{PRINCIPIO CONSTITUCIONAL DE LOS DERECHOS DE ASOCIACIÓN}

La Constitución Política, fuente primaria del Derecho Comercial en Colombia le confiere a los ciudadanos la libertad de organizarse como grupo para desarrollar los fines de su actividad asociativa. La norma de normas contiene un variado articulado que se refiere a la formación empresarial. Los artículos más importante en materia son: el 38 y el 333, sobre la libertad de asociación y libertad de empresa e iniciativa privada, respectivamente.

La libertad de asociación es considerad un derecho que corresponde a toda persona, y por lo tanto, "se garantiza el derecho de libre asociación” para el desarrolla de las distintas actividades que las personas realizan en sociedad". Este derecho, como lo ha sostenido la Corte Constitucional, tiene su raíz en la libre voluntad de las personas, que deciden perseguir fines lícitos a través de una organización unitaria en la que convergen, según su tipo, los esfuerzos, recursos y demás elementos provenientes de sus miembros y que sirve de medio para la realización del designio colectivo. A la libre constitución de la asociación- sin perjuicio de observar los requisitos y trámite legales instituidos para el efecto-, se adiciona la libertad de ingreso a ella y la libertas de salida, para completar el cuadro básico de esta libertad constitucional que reúne así dos aspectos, un positivo y otro negativo, sin los cuales habría respeto a la autonomía de las personas (Corte Constitucional, Sent-041 de 1994 M.P. Eduardo Cifuentes Muñoz).

Como podemos observar, el derecho de asociación es de doble vía, por cuanto no sólo otorga la posibilidad de unirse una organización, sino de igual modo determina la desvinculación o separación de la misma, es decir: el derecho de asociación bien puede manifestarse mediante la integración o el acceso a una organización conformada con 
cualquiera de estos propósito y/o manifestándose mediante la negación para hacerse parte de una organización determinada o desvinculándose de ella. Las dos facultades han sido objeto de reconocimiento institucional, pues constituyen un legítimo ejercicio tanto la cláusula general de libertad como de las libertades de pensamiento, expresión y reunión (Corte Const. Sent.C-792 de 2002, M.P Jaime Córdoba Triviño). Entonces, es más una facultad libre y voluntaria que tienen todas las personas de organizarse con un fin común lícito (Corte Const. Sent. C-272 de 1994 M.P Carlos Gaviria Díaz).

Esta facultad se videncia en otras libertades constitucionales que se encuentran reseñadas en el artículo 333 de la Constitución y que son inherentes al individuo y, en la medida en que se hagan efectivas, implican obligaciones y suponen responsabilidades, dichas libertades son:

Libertad de empresa: Es un derecho de carácter económico constitucional que se reconoce a favor de los empresarios. Es la libertad para ejecutar o desarrollar una determinada actividad y que otorga la potestad de crear, elegir y dirigir el tipo de empresa que desee formarse. Esta libertad es la base del desarrollo económico y otorga al individuo la facultad de desarrollar un objeto social con ánimos lucrandi, pero dentro de las limitaciones impuesta por la constitución Política y las leyes por razón de la moral, las buenas costumbres, la utilidad pública y el interés social.(Peña. 2012, p, 20.).

La iniciativa privada: es un derecho que se reconoce a toda persona para participar en determinado sector económico y cuyo fin es lograr un beneficio de carácter económico. La característica principal de la iniciativa privada es que el capital invertido no procede del gobierno si no de los particulares, es decir, todo aquel que tenga una empresa grande o mediana conforma la iniciativa privada. 
La libertad económica: es un Derecho Constitucional que otorga la potestad de escoger y dedicarse libremente a una determinada actividad económica. Esta libertad se encuentra enmarcada dentro de determinados deberes y derechos, uno de los cuales es la garantía de la propiedad privada que cumple una función de carácter social y ecológico. El Estado evitará que sea restringida y controlará cualquier abuzo originado por la posición dominante en el mercado; además delimitará el alcance de su libertad, si así lo exige el interés social.

Libre competencia económica: La Libre competencia económica es un derecho a disputar con otro competidor dentro del mercado sin ser discriminado. Su objetivo principal es promover la competencia entre a empresa existente en el mercado y la calidad de bienes y servicios a un bajo precio. Esta libertad supone responsabilidades, y por lo tanto no excluye la inherencia del estado para alcanzar determinados fines como son los consagrados en los artículos 64,65 y 66 de la Constitución Política colombiana.

\subsection{LA LEGISLACIÓN COMERCIAL EN COLOMBIANA}

Para nuestro país a pesar de estar bajo la conquista y colonización del yugo español, en el año 1953 se adoptó el primer Código de Comercio, elaborado sobre los principios del Código de Napoleón y reproducción casi exacta del Código Español de 1829, que derogo en forma expresa las ordenanzas de Bilbao.(Rojas. 1981.P. 38).

Durante la etapa presidencial de unificación política y administrativa de RAFAEL NUÑEZ en el 1887, se acoge el Código de Comercio del estado de Panamá que era lo más avanzado en todo este territorio colombiano y a su vez había acogido el Código de Comercio Chileno que al igual que Colombia era inspirado por el Napoleón , 
este rigió hasta finales del años 1971 ; luego lo sustituyo el Estatuto actual que fue expedido el 27 de marzo de 1971 y entro en vigencia el 1 de Enero de 1972, como se advierte en el artículo 2033 .(Decreto 410 de 1971).

\subsection{AUTONOMÍA PRIVADA DEL ACTO O CONTRATO SOCIETARIO}

Como resultado de los principios liberales de la Revolución Francesa, desde los códigos Napoleónicos nuestras leyes reconocen la potestad reguladora que emana de los propios particulares, a través del acto o contrato, para nuestro caso o contrato de estirpe societaria.

Se menciona y protege en nuestro derecho obligacional, entonces, el denominado postulado de la autonomía de la voluntad privada, para hace referencia a la facultad que tienen los contratantes, como árbitros naturales de sus relaciones jurídicas o de auto determinarse o fijar las reglas o normas que ha de regir sus distintos vínculos obligacionales, desde su nacimiento hasta su ejecución final. El contrato es una ley para las partes, es la máxima a través de la cual nuestros códigos erigen en fuente relativa de derecho (Art. 1062 del Código Civil y art 4 del Código de Comercio).

En el ámbito del derecho societario dicha autonomía de los particulares para auto regularse es cada vez más creciente y en el derecho contemporáneo se manifiesta especialmente en la creciente habilitación legal para quesean los propios asociados quienes configuren la forma o tipo de su sociedad (Espina 2003. Pg 12). 
De alguna manera esta tendencia nos ha alcanzado a través de la legislación que dio cabida en Colombia a las Sociedades por Acciones Simplificadas (SAS). La capacidad normativa de los actos jurídicos encuentra, no obstante, una muralla infranqueable en las disposiciones de la legislación que tienen un carácter imperativo.

El poder regulador de los particulares de sus propias causas no puede llegar al punto de alterar, modificar o derogar las disposiciones que se informan en razones de orden público, de la tutela del interés general. Es por ello que el art. 4 del Código de Comercio reconoce el poder vinculante de los contratos sólo de preferencia sobre las normas legales supletivas. (Martínez. 2010. P. 39). El orden jurídico reclama que las leyes imperativas sean intangibles e inolvidables por los particulares, a riesgo que las convenciones privadas adolezcan de nulidades que afecten la misma eficacia del acto o contrato.

En este orden de ideas, debemos distinguir, desde el punto de vista del contrato y su relación con la legislación como las normas imperativas de la simplemente dispositivas. Las primeras no pueden ser derogadas por la autonomía de la voluntad privada, como ha quedado dicho. De ellas abundan los ejemplos, dada la creciente tendencia publificadora de la regulación de los derechos de los minoritarios en las sociedades públicas y los derechos de los minoritarios en las sociedades públicas y del derecho de la información de los mercados, para citar dos casos; así las disposiciones al respecto son todas dados de orden público que deben respetar los particulares en su tratativa. (Martínez, 2010 .p. 223- 225). 


\subsection{EL CONTRATO SOCIAL}

Según los términos del artículo 98 del Código de Comercio Colombiano, basado en los principios de la legislación Francesa por la teoría contractualita (Brunetti, 1960, tomo 1.P.165.) podemos definir la sociedad como el contrato en que dos o más personas solían hacer un aporte, con el fin de distribuirse las utilidades obtenidas en la actividad social. Distinguimos así en la sociedad estos elementos esenciales: como la pluralidad; El aporte; la intención de asociarse (animus societatis), la Distribución de utilidades y el beneficio común.

1.5.1. La Pluralidad como elemento esencial. Este es el elemento de análisis que nos lleva a la investigación para poder aclarar su concepto o en su defecto determinar la evolución de este con las nuevas tendencias del contrato social unilateral o la mejor dicho la teoría unilateral que bien seria llamada, para muchos autores clásicos y modernistas no existe "la sociedad de un solo socio", porque la sociedad tiene su origen en un contrato que por definición es un acuerdo de voluntades. (Rojas Carlos, 1981, P.38).

ARTICUlO 1495. Del Código Civil Colombiano DEFINICIÓN DE CONTRATO O CONVENCIÓN. Contrato o convención es un acto por el cual una parte se obliga para con otra a dar, hacer o no hacer alguna cosa. Cada parte puede ser de una o de muchas personas.

Con el contrato entonces se regularizan entre los particulares con el fin de obtener un lucro o ganancia, por el cual las personas se obligan, se ligan o se atan. en palabras de Justiniano (institutas 3.13 proemios) es una obligatioest iuris vinculum quo 


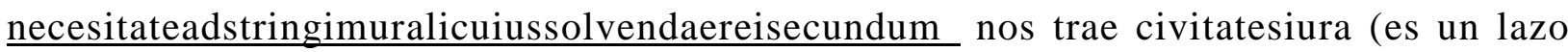
de derecho que nos constriñe en la necesidad de pagar alguna cosa conforme al derecho de nuestra ciudad).

Además la importancia de las sociedades en la economía moderna radica precisamente en la necesidad de unir esfuerzos y recursos, (Narváez. 1996. P. 86) para lograr una organización que compita ventajosamente en la producción o distribución de los bienes y servicios, que a la vez derive mayores utilidades.

La pluralidad es un requisito esencial para la constitución de todo tipo de sociedad y se exige durante todo el término de su vida activa, hasta el punto que su falta constituye una causal de disolución. De otro lado debe existir o tener en cuenta una pluralidad mínima u obligatoria que es de dos personas para todo tipo de asociación, con excepción de las sociedades por acciones en las que se requiere un mínimo de cinco, sólo en las sociedad limitada existe un límite máximo de 25, puede asociarse, además, sólo personas naturales o únicamente personas jurídicas o concurrir unas y otras en la sociedad.

El doctor Lisandro Peña Nossa, en su obra de derecho societario establece que la pluralidad de socio, en lo referente al artículo 98 del código de comercio, excluye la posibilidad de crear sociedad unipersonal, No obstante fueron creadas a través de los artículo 22 de la Ley 1014 de 2006 y el Decreto reglamentario 4463 del mismo año regularon la figura unipersonal de la sociedad, que posteriormente será debatido más adelante con argumentos jurídicos de peso por tratadistas como HUMBERTO MARTINEZ NEIRA al mal interpretar de manera abusiva y desmedida la autonomía de voluntades por algunos tratadistas dice Martínez Neira. 


\section{CONCLUSIONES}

De este primer capítulo podemos concluir que hacer una investigación sobre los conceptos de pluralidad y autonomía dentro del derecho comercial es pretender tomar dos caminos epistemológicos. Por un lado es embarcarse en un proceso que tiene la tendencia a llevarnos a un fracaso conceptual por la falta de fuentes y trabajos que versen sobre la naturaleza de los conceptos que son necesarios para entender la dinámica de las sociedades SAS, como lo son el concepto de autonomía y el concepto de pluralidad en los socios. La carrera conceptual de realizar una tesis sobre bases tan débiles en la investigación nos enfrenta a retos complejos, pues se debe explotar al máximo cada definición cada palabra expresada en los contratos y realizar una hermenéutica de las formas como se están desarrollando en este tipo de sociedades, los conceptos de autonomía y pluralidad. Por otra parte, el camino de emprender un proyecto donde pocos han querido abonar el terreno nos presenta una oportunidad para iniciar una línea de investigación sobre el desarrollo conceptual al interior de una dinámica comercial.

El ejercicio académico del análisis conceptual abrirá las bases para estructurar una iniciativa de investigación sobre la autonomía y la pluralidad en el contrato de socios. 
Esta investigación descriptiva, se basa en el análisis filosófico y epistemológico del concepto de pluralidad y autonomía en el contrato societario que se establece en la legislación colombiana en especial en el artículo 98 de la legislación comercial, haciendo un estudio desde la metodología del derecho societario colombiano para explicar la pertinencia, dinámica o ausencia de estos conceptos en el desarrollo del contrato societario colombiano han introducido la pregunta metodológica sobre los componentes epistemológicos del análisis de los conceptos en el derecho privado, comercial, y especial en el societario.

Como la epistemología y la filosofía del derecho son sub-disciplinas fundamentales de las ciencias jurídicas, se estudiará en este proyecto de tesis de maestría, la genealogía del concepto de pluralidad (Narváez. 1996. P. 86) y autonomía en los casos de contrato societario para establecer la interpretación, como se han empleado, que tipo de ventajas y restricciones se derivan de la interpretación de estos conceptos, cómo son entendidos en unos casos y como se leen en otros. La importancia de este proyecto radica en la tesis que en el derecho privado y de contratación, en lo relacionado específicamente en contrato societario se piensa que hay un gran margen de interpretación subjetiva de los miembros al momento de establecer las ganancias, beneficios, responsabilidades, derechos y deberes. La hipótesis central de esta investigación es que el grado de subjetividad en la interpretación de los conceptos pluralidad y autonomía en la legislación comercial en especial del contrato societario deja mucho margen de actuación a los sujetos que participan en el asunto, generando unas dinámicas de autonomía y pluralidad (Villamizar. 2010. p. 80) de normas dentro del proceso. Esta hipótesis está sustentada en la revisión documental sobre el contrato societario, donde las investigaciones actuales apuntan a la revisión de los conceptos básicos y a la comparación con otros países para intentar comprender la dinámica interna que se plantea en el contrato societario (Pinzon.1984.p.14 y15) . 
La investigación se centra en el análisis del concepto de pluralidad (Universidad Nacional /IDE; 1993, 3 de febrero) y autonomía dentro del contrato societario, y por contrato societario se entiende como la unión de fuerzas materiales e intelectuales comerciales con beneficio común que propende generar utilidades a los asociados. (Vivante, 1932.p.32) Pero esas utilidades y beneficios son interpretados de una multiplicidad de formas apelando a los conceptos de pluralidad y autonomía dentro de la estructura del contrato (Martínez. 2010.p.223) así que desde la investigación descriptiva es útil hacer una revisión de las formas como se interpretan dichos conceptos en este escenario. "Por pluralidad se entiende la unión de dos o más personas esenciales ya sea natural o jurídica como requerimiento para la constitución de una sociedad" (Rocha, 1969.p. 32) que implica una adaptación normativa al conjunto de los hechos que se presentan en esa constitución de la sociedad. Y por autonomía entendemos la capacidad de tomar decisiones dentro de un marco jurídico acorde con las circunstancias históricas y los beneficios sociales y económicos que se presenten (Rodríguez.1977.p.13). Partiendo de estas concepciones básicas se realizó una búsqueda bibliográfica importante para establecer un marco teórico sólido que permita la lectura de estos conceptos en el contrato societario.

La innovación en investigación en las ciencias del derecho no sólo se fundamenta en la emergencia de nuevas temáticas y tesis, también radica en la revisión socio-crítica de los conceptos y la interpretación de los mismos en los procesos jurídicos. Se trabajó desde la metodología del derecho interno tomando 2 casos de contrato societario para hacer la revisión, comparación y aplicación del concepto de pluralidad y autonomía. Como el derecho es una ciencia social y económica se mirará las relaciones de poder que se establecen en este tipo de contratos societarios, ¿cómo se ha integrado el concepto de pluralidad y autonomía en la toma de decisiones y en la adjudicación de responsabilidades?: El tema del estudio conceptual de la pluralidad y la autonomía en el contrato societario se toma para observar en la legislación un amplio marco de subjetividad en la aplicación y respeto por las normas en el contrato societario; es decir que al revisar los contratos, se ha encontrado que se interpreta el concepto de pluralidad 
como un componente que permite fijar normas alternas al interior del colectivo de socios y se ha hecho uso de la autonomía muchas veces para fijar responsabilidades, derechos y deberes que en algunos casos no están contemplados en la Ley o se les hace una interpretación contraria a la naturaleza de las normas que rigen en el contrato societario. La observación empírica de los contratos societarios nos ha llevado a reflexionar y a tomar como objeto de estudio en esta tesis de maestría la interpretación y dinámica de dos conceptos que son claves y que hay que entender a profundidad en el derecho privado y el derecho comercial y más ahora por los procesos de globalización y libre comercio en el que vive el país.

Por ejemplo a través de la expedición del Decreto 4463 del 15 de diciembre de 2006, quisieron realizar una maniobra engañosa a la Ley antes mencionada para dar vida a los intereses del gobierno de la época y a las Cámara de Comercios, pero dándose el debate jurídico intervino la Corte Constitucional mediante Sentencia C-392 del 2007, manifestando con eufemismos que la Ley 1014 no había cuestionado la naturaleza contractual de la sociedades, lo que resultaba arrojar que las sociedades tenían que siempre contar con el elemento pluralidad, lo que por ultima instancia se demandó ante el Consejo de Estado, a través del Decreto y con un fallo del magistrado ponente Rafael Ostau De la Font, el Consejo de Estado declaró la nulidad del mencionado Decreto. Lo más grave aún es que los intereses de algunos sectores que tramitaron la Ley 1258 de 2012, siendo contraria y violatoria a los preceptos señalado en el artículo 98 y 898 del Código de Comercio, hoy objeto de análisis en esta tesis, obviando los principios rectores como el de la cosa juzgada dando en los fallos de la Corte Constitucional y del Consejo de Estado, elementos de orden constitutivo tales como: la pluralidad y la autonomía en el ánimo societatis que imposibilitan la creación de una sociedad anónima simplificada por una persona natural, lo que conlleva la investigación a considerar los conceptos jurídicos de contrato - sociedad y de sus conceptos fundantes como pluralidad y autonomía. 
Entonces ¿Cómo se ha interpretado, cual ha sido la descripción y los usos de los conceptos de pluralidad y autonomía en el contexto del contrato societario en Colombia?: En el contrato societario en Colombia hay mucho margen subjetivo y de interpretación de la Ley que permite la pluralidad de normas en su interior y una concepción de autonomía que se convierte en una relación de poder al establecer responsabilidades, ganancias, derechos y deberes. Como ocurre con la Ley 1258 de 2012, que es inconstitucional, por violentar decidida y reflexivamente el principio de la cosa juzgada constitucional en torno a la pluralidad y a la autonomía societaria. Es decir que la hipótesis de trabajo que se defiende y se demuestra en esta tesis de maestría, versan sobre la idea que la norma vigente del contrato societario en Colombia en razón a la pluralidad y autonomía societaria, le dan una interpretación contraria a la teoría contractualista originaria en Colombia, mostrándose en el concepto de pluralidad y autonomía en la práctica muchas veces contrarios a lo que plantea la Ley 1258 de 2012.

En suma esta hipótesis busca presentar a través de pruebas documentales y empíricas recogidas del análisis de los contratos como se emplea e interpretan los conceptos de pluralidad y autonomía subjetiva de la Ley en el contrato societario, pues como lo habíamos expresado en la introducción de la tesis, los elementos subjetivos de la norma y la dinámica interna de los contratos, son elementos de poco análisis en el país.

Es importante abordar el problema de investigación que se ha planteado para poder tener en nuestro país una formalidad en la constitución de sociedades comerciales, de ser un derecho reglado, de preservar las instituciones jurídicas (teoría de la institución) (Hauriou y Renard. 1938.p.4.) unir esfuerzos de buscar una cultura de unión, y por su puesto precisar los términos y la definición que se establece la Ley societaria y contractual. 
Para poder aclarar los conceptos básicos de la Ley de SAS, es importante hacer una revisión crítica de los mismos para analizar "la buena fe" de los empresarios y posibles socios que se acogieron a las reglamentaciones que se proponen en el contrato societario. Los estudiosos del tema societario plantea la urgencia de revisar los conceptos de pluralidad y autonomía que son fundamentales en la teoría contractualista (Vivante.1932.p.32), (Peña.2011.p.19.), para poder contribuir desde el avance científico y filosófico de este tema, que es de mucha relevancia por los cambios económicos y sociales que está viviendo el país y su apertura con los mercados internaciones y el fortalecimiento de la inversión extranjera.

El interés académico de este trabajo se fundamenta en la comparación de las interpretaciones de los conceptos de pluralidad y autonomía en el contrato societario con las normas de los países latinoamericanos, para así tener una referencia de la variabilidad, semejanzas y continuidades en el proceso de la interpretación y aplicación de estos conceptos en el derecho privado y comercial.

El aporte de este trabajo es mostrar desde el punto de vista conceptual a la unificación de conceptos jurídicos que propenda por la construcción de un derecho reglado lleno de formalidades acorde con las necesidades mercantiles, analizando la interpretación y empleo de los conceptos de pluralidad y autonomía en el contrato societario en Colombia, por parte de los socios, a su vez haciendo una revisión desde la perspectiva del derecho comparado, cómo los países Latinoamericanos han trabajado en la claridad y unificación de conceptos de pluralidad y autonomía en el contrato societario para establecer coherencia normativa y jurídica en el proceso de estructuración de las sociedades comerciales.

Lo más novedoso de la reflexión conceptual de la autonomía y la pluralidad en el contrato es poder develar las relaciones de poder y las interpretaciones subjetivas que se han hecho a los conceptos de pluralidad y autonomía en el contrato societario para 
establecer responsabilidades, ganancias y compromisos de los socios al interior de dicha sociedad, a su vez, comprender la dimensión jurídica de los requisitos esenciales del contrato societario mercantil establecidas en la norma comercial, que en consonancia a Ley que rige las sociedades anónimas simplificadas.

Esta investigación tiene como objetivo abrir la discusión sobre la utilización de los conceptos y la revisión de los mismos para construir consensos al momento de la aplicación de las normas y las leyes en el derecho contractual, civil y comercial. El estudio de los conceptos de pluralidad y autonomía en el contrato societario abrirá líneas de investigación para el análisis crítico sobre los alcances y limitaciones de la Ley en el contrato societario. 


\section{CAPITULO 2.}

\section{DEL ANÁliSIS DE CONCEPTO PLURALIDAD Y AUTONOMÍA EN EL CONTRATO SOCIETARIO}

Con este capítulo buscaremos desentrañar o mejor dicho demostrar lo importante que es en el individuo en la relación con sus semejantes; el crecimiento de éste con su entorno, la comunidad y porque no, la sociedad proyectada, siempre estarán sujetas a vínculos contractuales que permiten el fortalecimiento de sus capacidades y más si hablamos de sociedades comerciales para conquistar los mercados.

Legislación colombiana en su artículo 98 del Código de Comercio tienen su origen en la corrientes francesas como resultado de los principios liberales de la Revolución Francesa ha sido de gran importancia en el crecimiento de la cultura jurídica Latinoamericana y en especial para los colombianos desde los códigos napoleónicos, nuestra disposiciones reconocen de donde emanan, de igual forma se adopta las teorías como la del acto o del negocio jurídico, la primera corriente francesa que consiste en la manifestación de la voluntad ya sea uní o bilateralmente produciendo efectos jurídicos, mientras que la segunda que es una corriente italiana, en el cual prima la voluntad privada declarada con un fin preponderante económico produce efectos jurídicos legales ya sea unilateral, bilateral o plurilateral que produces interese privados y la Teoría de Institucionalista que constituyen el pilar del régimen de toda sociedad e incorpórala a nuestro ordenamiento jurídico; "lege de data” puede afirmase que es un contrato, como ya hemos sabido y estudiado la importancia en el análisis de 
los concepto pluralidad y autonomía en los contratos societario basado des la definición del Código Francés en el Art. 1832: Establece que la sociedad es un contrato por el cual dos o más personas convienen poner cualquier cosa en común, con el objeto de partir el beneficio que pueda resultar de ello "Sociedad es un Contrato". (Rodríguez, 1977. P. 27).

Tal como lo señala el concepto anterior se puede terminar que el concepto sociedad crea una personalidad jurídica de comunidad lo que aglomera varias partes (pluralidad) que es reconocida por el estado y con base a los acuerdos establecidos en ella pueden estipular normas supletivas respetando la normas imperativas contractuales del contrato social .

\subsection{ANÁlisis DEL CONCEPTO PLURALIDAd DEL CONTRATO DE SOCIEDAD}

2.1.1. Del Concepto Contrato Societario. La sociedad a partir de su definición como contrato desde su origen romano se atenido en cuenta como un acto jurídico plurilateral y la regulan como un negocio jurídico particular; por lo tanto la asociación mercantil se tiene como un acuerdo de voluntades en que se termina relaciones jurídicas y económicas entre los partes o socios porque su origen es un contrato estas teorías fueron reconocidas por las Escuelas institucionalistas francesas, expresadas en las obras de Renard, Hauriou y posteriormente en Ripert, escogidas por los alemanes y luego avalada en la obra clásica de los italianos Messioneo y Brunetti, ha podido desconocer que el origen de la sociedad es un contrato. Mucho menos que el contrato, entendido como acuerdo de voluntades que sirve como fuente obligacional de los socios, gobiernan las relaciones internas de estos en los Estatutos. (Ripert. 1954. P. 20.) 
No cabe duda, entonces, que al derecho de las sociedades se llega a través de la teoría del contrato y, por ende, el derecho de los contratos. (Martínez. 2010. p.2 .). lo que nos dice es que la sociedad se reputo un acto voluntario sinaglamatico y conmutativo que estipulan obligaciones y derechos recíprocos entre las partes generan intercambio de prestación. Como quiera que el acuerdo da origen a esta asociación se tipifica como un acuerdo de dos o más partes para constituir y regular relaciones jurídicas patrimoniales de conformidad al art. 864 del Código de Comercio.

En este orden de ideas y teniendo encuentra el origen de las sociedad como elemento contractual el artículo 98 del código de comercio que lo define "Por el contrato de sociedad dos o más personas se obligan a hacer un aporte en dinero, en trabajo o en otros bienes apreciables en dinero, con el fin de repartirse entre sí las utilidades obtenidas en la empresa o actividad social.

La sociedad, una vez constituida legalmente, forma una persona jurídica distinta de los socios individualmente considerados."(Brunetti. 1960. P.3.) (Sentencia Corte Constitucional T-484 de 2005. M.P. Alfredo beltran).

Se resalta los elementos esenciales de la ley, la doctrina y la jurisprudencia han detallado como son: La pluralidad de socios, que determina quienes intervienen en la sociedad, el tipo de sociedad por la pluralidad mínima y máxima para determinar qué tipo de sociedad se efectuara entre otros , El aporte ya sea en dinero o especie, el ánimo de lucro, buscar el beneficio económico, el animus societattis y beneficio común como figuras doctrinales por lo que son muy intrínsecas en algunas clasificaciones de sociedad. 
2.1.2. De la pluralidad y los contratos societarios o convención. La Pluralidad de socios como requisitos esencial emana de la naturaleza contractual de la sociedad. Porque, como ya lo hemos dicho no puede existir acuerdo de voluntades entorno a un negocio jurídico, sino a partir de la existencia de una pluralidad de agentes que consientes como por ejemplo determinara la pluralidad mínima y la pluralidad máxima, como regla para constituir la sociedad para que subsista debe haber por lo menos dos socios o declaraciones de voluntades. (Grisoli, 1976.P.40)

De allí se critica la Ley 1258 de 2008, cuando se insertó en el artículo primero la posibilidad de realizar sociedades con una sola persona, realizando un sesgó a la ley comercial, después de un debate duro en sacar a las sociedades unipersonales del contexto societario con el fallo del consejo de estado declarado la nulidad del decreto 4463 de 2006 que quiso revivir la sociedad unipersonal. tratadistas como Francisco Reyes Villamizar y Alberto Becerra respaldan la teoría de la unilateralidad (SAS), manifestando que la pluralidad de socio es un problema semántico y es un concepto devaluado; por lo tanto lo que buscan es crear sociedades agiles en el mercado y sostienen la tesis de sociedades de personas con un solo socio como es la SAS. En esta investigación demostramos que los argumentos planteados por los doctrinantes anteriores violaron las normas imperativas del derecho societario colombianos como son las consagradas en los artículos 4, 98 y 864 del Código de Comercio Colombiano y no, es que la unilateralidad con la sociedad sea un problema semántico es una figura jurídica que tiene un contexto filosófico y epistemológico que tiende a desaparecer o ser mal interpretada cuando pretenden demostrar que el elemento pluralidad es irrelevante en un marco económico actual, porque pretenden burlar el concepto de pluralidad y sociedad . (Ministerio de Justicia, Comisión Redactora del Código de Comercio, T.II. Bogotá, 1958. Art.591.) 
La institucionalidad de la figura (pluralidad) - contrato debe ser relevante por ser principio de nuestro ordenamiento legal contractual, por tener su origen en las disposiciones contenidas en la teoría contractualita clásica y en el marco del fallo proveniente del máximo órgano jurisdiccional colombiano quien corrobora lo manifestado en una célebre sentencia (Sentencia Corte suprema de Justicia, Sala Civil del 13/12/1980).

Esta pluralidad no se aplica en las sociedades por acciones simplificadas, y que podrán constituirse por una persona natural o jurídica (Ley 1258 de 2008, art.1), lo que ha causado traumatismo en la comunidad estudiantil y académica, el concepto de la pluralidad con este tipo de sociedad. Además "nadie puede contratar consigo mismo como lo firma Jorge Humberto Botero". (Botero, 1986.P.82.)

\subsection{EL CONCEPTO DE AUTONOMÍA}

La "autonomía de la voluntad", esa hermosa matriz del derecho privado liberal clásico ("quien dice contractual, dice justo"), es actualmente un instrumento importante de regulación de las relaciones sociales. La observación del funcionamiento real efectivo de esta herramienta legal, revela la identidad del individuo social postmoderno, cuya libertad es a la vez inmensa e irrisoria, fuente de poder ilimitado y de sujeción servil a las directivas de organizaciones, públicas y privadas, que establecen lo que se debe querer para querer eficazmente. Ejercer esta prerrogativa significa adherir a normas que se imponen de hecho independientemente de su fuente, más en una medida que puede ser determinada. Ello ha llevado a cuestionar la importancia del principio de legalidad en los contratos estatales, pues en la actualidad la autonomía de la voluntad se plantea como garantía eficaz contra la arbitrariedad del Estado. (Amazo.2007.P.181207). 
2.2.1. Autonomía de la voluntad. La sociedad es una entidad esencialmente evolutiva que busca en su regulación jurídica estar acorde con la realidad de la misma, por lo tanto, las instituciones jurídicas no son más que un reflejo que se va transformando a medida que las modalidades extrínsecas influyen con las intrínsecas, modalidades decisivas en la constitución psicológica de un pueblo. (FLOREZ, 1936, P. 205).

Entrar en el campo de la autonomía de la voluntad implica acercarnos a nuestra temática jurídica y retomar la evolución que el concepto ha tenido en el derecho, así como los inconvenientes que se han presentado alrededor del tema, sin buscar hacer una recopilación completa de la noción, porque sería demasiado ambicioso, sino tomar conceptos que contribuyan a tener una visión integral de este principio que ha permanecido en nuestro sistema jurídico. No es extraño que la autonomía de la voluntad haya sido la que hubiera regido por mucho tiempo las relaciones contractuales desde la Edad Media hasta fines del siglo XVIII porque sólo se exigían requisitos de forma para su validez, puesto que lo esencial era que existiera el libre consentimiento. Kant es sin duda quien le da mayor vigor a la autonomía de la voluntad, al hacer depender toda la actividad del hombre de las sensaciones externas, y Rousseau, que la lleva hasta la concepción del Estado en su contrato social, para que posteriormente en el Código de Napoleón se establezca que el contrato es una ley para los contratantes siempre que no vaya en contra del orden público.

De esta manera, el concepto tradicional de la autonomía de la voluntad encuentra sus raíces en la filosofía individualista que se desarrolló desde el siglo XVII con una influencia también del cristianismo, en donde se consideraba al hombre libre por esencia y sólo podía obligarse si era de su voluntad, por lo que la fuente únicaautónoma de la ley era ella misma. Por ello la palabra autonomía remite a la capacidad de un grupo para darse normas, es decir, poseer potestades normativas. Pero en el ordenamiento jurídico ese reconocimiento ha variado a lo largo de la historia, pues 
depende igualmente de los regímenes políticos imperantes en cada lugar, aun cuando la esencia de esa autonomía es que los individuos puedan dictar normas que el Estado asumirá como propias al conceder un vigor semejante al de la ley. (BALLESTEROS, 1999, p. 20.).

Así es como la autonomía de la voluntad, cuyo recorrido histórico la arroja como un principio esencial reconocido en las legislaciones contemporáneas y que representa en mayor grado el concepto de participación ciudadana, se constituyó como uno de los principales cambios sociales que fueron incorporando las revoluciones inglesa, norteamericana y francesa en los años 1688, 1776 y 1789, respectivamente. Y fueron incorporándose porque la voluntad individual que posee en el derecho un verdadero poder creador de obligaciones y derechos es lo que hace que la autonomía de la voluntad tenga eficacia jurídica y sea considerada como una ley entre las partes, manifestada en la formación del acto jurídico y determinación de sus efectos, fruto de dicha autonomía. (AMAZON, 2007,P,182)

Así mismo, su componente jurídico no es más que el reconocimiento hecho por el ordenamiento jurídico de dicho principio y de la forma en que el legislador le ha permitido permear las esferas de la administración de justicia; así, nuestra legislación consagra este principio (artículo 16 y 1602 del Código Civil, entre otros) estableciendo que todo contrato legalmente celebrado es ley para los contratantes y sólo puede ser invalidado por consentimiento mutuo o por causas legales, con la precisión de que en su ejercicio debe primar el respeto del orden público y las buenas costumbres, es decir, aunque su reconocimiento es expreso, se hace necesario que el Estado limite su ejercicio.

Por tal razón, la autonomía de la voluntad permite que toda persona legalmente capaz, pueda obligarse. Por una vía alternativa adecuada (en virtud de la capacidad de 
disposición que la ley le otorga), mediante la celebración de contratos en los cuales se pacten cláusulas que no vayan en contra de las limitaciones ya enunciadas por la Corte Suprema de Justicia, Sala Civil, ha sido reiterativa en sostener que uno de los principios que gobiernan los contratos es el contenido en el artículo 1602 ya mencionado. En sentencia de casación del 17 de mayo de 1995, M.P. Pedro Lafont Pianetta, dijo:

(...) Principio de la autonomía de la voluntad. 1. Como es suficientemente conocido, uno de los principios fundamentales que inspiran el Código Civil es el de la autonomía de la voluntad, conforme al cual, con las limitaciones impuestas por el orden público y por el derecho ajeno, los particulares pueden realizar actos jurídicos, con sujeción a las normas que los regulan en cuanto a su validez y eficacia, principio este que en materia contractual alcanza expresión legislativa en el artículo 1602 del Código Civil que asigna a los contratos legalmente celebrados el carácter de ley para las partes, al punto que no pueden ser invalidados sino por su consentimiento mutuo o por causas legales (...). (Negrillas de la autora)

Con lo anterior se indica que lo acordado en un contrato se debe hacer con el consentimiento de las partes, con unos requisitos que podríamos enunciar de la siguiente manera:

1. La capacidad legal para comprometerse: los individuos que deseen acceder o celebrar un contrato deben ser plenamente capaces de comprometerse o disponer sobre los objetos, bienes o servicios sobre los cuales recae la práctica del respectivo contrato ya sea para disponer, transigir, conciliar, etc, tal como se observa en el texto del artículo 2470 de nuestro Código Civil: “(...) no puede transigir sino la persona capaz de disponer de los objetos comprendidos en la transacción".

2. La materia objeto de contratación: son todas aquellas cosas (materiales o inmateriales) sobre las cuales la ley faculta para disponer y para cuya identificación existen dos sistemas, uno que identifica en forma genérica las cosas sobre las cuales se 
puede o no negociar, y otro que hace referencia de manera taxativa y por exclusión a las materias sobre las que no es válido disponer. Este último se establece en nuestro sistema legal, el cual. Excluye, entre otros, el estado civil de las personas y los derechos laborales ciertos e indiscutibles establecidos en la ley, el pacto o convención colectiva de trabajo vigente, el laudo arbitral o los reconocidos expresamente por el empleador. Así, las relaciones entre la administración y el particular deben fundarse en el acuerdo de voluntades, del que emanen las principales obligaciones y efectos, de conformidad al Código Civil en el artículo 1602, en donde exista una confluencia de las manifestaciones de la voluntad de cada contratante respecto de los aspectos esenciales del contrato sin necesidad de un requisito adicional. (CÁRDENAS; 1994, P. 155-158.).

De tal manera que la trascendencia del acuerdo de voluntades que constituye la esencia de un negocio jurídico implica que el acuerdo de las partes legalmente celebrado es una verdadera ley que se debe acatar y cumplir, y que por ello debe imprimir una obligatoriedad que regule las principales relaciones jurídicas. Así mismo, la Corte Constitucional analizó la figura de la autonomía de la voluntad privada de la cual hace una erudita reconstrucción histórica para identificar la forma como esta se ha transformado a través del tiempo. La Corte Constitucional precisa:

(...) la autonomía permite a los particulares: i) celebrar contratos o no celebrarlos, en principio en virtud del solo consentimiento, y, por tanto, sin formalidades, pues éstas reducen el ejercicio de la voluntad; ii) determinar con amplia libertad el contenido de sus obligaciones y de los derechos correlativos, con el límite del orden público, entendido de manera general como la seguridad, la salubridad y la moralidad públicas, y de las buenas costumbres; iii) crear relaciones obligatorias entre sí, las cuales en principio no producen efectos jurídicos respecto de otras personas, que no son partes del contrato, por no haber prestado su consentimiento, lo cual corresponde al llamado efecto relativo de aquel (...) Corte Constitucional, Sentencia C-341, 3 de mayo de 2006, M. P. Jaime Araujo Rentería, exp.D-6020. 
Frente a la libertad para contratar ya enunciada, debemos tener en cuenta que el principio de la autonomía de la voluntad se consideró fundamental en la formación de los contratos privados y ha merecido importancia en la aparición de la llamada crisis del contrato, tema muy controvertido y polemizado por iusprivatistas de la mitad del siglo XX hasta nuestros días (VALLESPINOS, 1984, P. 26.), que de una forma u otra ha sido asimilado o relacionado con el resquebrajamiento del principio de la autonomía, pero al igual que en todos los temas del derecho en general, el de la crisis del contrato es polémico: tiene detractores que rechazan su existencia por completo y defensores que le dan plena vigencia. Para los más fervientes defensores de la autonomía de la voluntad no cabe la posibilidad de hablar siquiera de tal crisis si por el contrario estamos ante un auge del contrato, donde cada día existen más de ellos y más especies de los mismos; otros (VALLESPINOS, 1984, P.30.), podrían identificarse con la escuela en contra de la existencia de crisis alguna diciendo que no existe tal, sino que se está buscando su punto de equilibrio; otros, según nuestro parecer, más acertadamente, hablan de una crisis, pero general del mundo contemporáneo y, por consiguiente, del hombre contemporáneo, que, en consecuencia, desencadena una crisis en todas sus manifestaciones, entre ellas las relaciones de sociedad que trascienden al mundo jurídico; otros, más radicales al pensar afirmativamente en la existencia de tal crisis, hablan de una despersonalización total del individuo, en donde el aceptante en la relación contractual pasa a ser un simple adherente que se someterá a unas condiciones generales predispuestas, eliminándose así toda posibilidad de autonomía privada en la realización del contrato.

Esta última ha sido una aproximación característica de la contratación estatal, que aparta de su regulación jurídica la autonomía de la voluntad por considerarla como un principio que rige los vínculos entre particulares y que no se encuentra contemplado para las relaciones jurídicas con entidades públicas o en el peor de los casos que se trata de un postulado en plena decadencia junto con la crisis del contrato. (AMAZO, 2007, P.188.) 
Podría decirse que el principio de la autonomía de la voluntad ha discurrido entre dos corrientes diferenciadas: la primera tiene su fundamento en la libertad de los hombres, de gran vigencia en los dos siglos pasados, por la influencia de los pensamientos empapados de un voluntarismo excesivo derivados de la Revolución francesa; la segunda también cuenta con importantes fundamentos, más recientes, de mitad del siglo XX, como la intervención del Estado en las relaciones de los particulares, en las que aún existen evidencias de la aplicación de la autonomía de la voluntad, pero con un poco más de límites, como se verá más adelante. En la actualidad, en la contratación estatal la autonomía de la voluntad con la que cuenta cada una de las partes no ha sido un tema tan libre o respetable, pues aún se considera que dicho principio rige sólo en el derecho privado y que para imponerlo como obligatorio requiere un reconocimiento legal.

Como se observa, la aplicación del principio de la autonomía de la voluntad no ha hecho parte de las interpretaciones que se le han dado por parte de la administración en la contratación pública, al considerar que su aplicación estricta como en el derecho privado le hace perder su esencia, pues los contratos estatales siempre obedecen a la satisfacción del interés general.

\subsection{LA AUTONOMÍA DE LA VOLUNTAD Y LA LIBERTAD CONTRACTUAL EN EL CONTRATO ESTATAL}

Al revisar el espíritu del proyecto de ley del Estatuto de contratación estatal, por la ponencia para segundo debate de la Cámara los Representantes Héctor Anzola Toro, Coordinador de Ponentes, Jorge Ariel Infante Leal, Edgar Papamija Diago, Luis Fernando Almario R. y Raúl Rueda Maldonado pusieron de presente que: 
“En su contenido se da un mayor campo de acción a la autonomía de la voluntad, sin perjuicio de las potestades excepcionales del Estado. Se trata de una normatividad que busca que el servidor público pueda desplegar toda su capacidad de innovación, gestión y administración para el cabal cumplimiento de los objetivos encomendados a la entidad pública a su cargo, con un claro y severo régimen correlativo de responsabilidad"

Al respecto invocaron lo dispuesto por el artículo 40 de la ley 80 que al señalar el contenido de los contratos consagra en su entender "la libertad de la entidad contratante para definir el contenido del contrato a celebrarse, siempre y cuando con ello no se contraríen normas de orden público. (M.P. Ruth Stella Correa, Consejo de estado, Sección Tercera, Exp. 26105).

En los procesos de contratación estableciendo un adecuado equilibrio entre autonomía de la voluntad y potestades excepcionales, por una parte y entre libertad de gestión y mayor responsabilidad, por la otra (BETANCUR, p. 174 y 175.) Autonomía de la voluntad que había sido reconocida por la jurisprudencia administrativa, mucho antes de su consagración expresa en la ley 80 como "núcleo esencial del negocio jurídico, en sus diversas manifestaciones. Importa para el asunto sub lite sólo resaltar la concerniente a la libertad negocial, norma medular del régimen de las obligaciones, según la cual las partes no sólo pueden celebrar todos aquellos negocios jurídicos que emerjan de la autonomía de la voluntad, sino pactar también condiciones negociales particulares, conforme al art. 1602 del CC., ajustando el contrato en cuanto a modo, tiempo y lugar para el cumplimiento de las prestaciones tal como lo señala la (Sección Tercera del Consejo de Estado M.P. Betancourt Jaramillo Exp. 4303), Por manera que como en el derecho común, la Administración también puede pactar con cierta libertad las cláusulas usuales según su naturaleza, siguiendo las reglas del derecho privado, a menos que exista disposición legal en contrario. 
Suele decir que como en el derecho común, la autonomía de la voluntad, en el contrato estatal también está limitada por el derecho positivo, sólo que en este caso el legislador está movido por un móvil particular: el reconocimiento de la función administrativa contractual. De modo que este principio no es absoluto y así lo ha reconocido de vieja data la Sala, sobre la base de que ésta no puede contravenir normas con fuerza de ley, de donde la capacidad de autodeterminación de los sujetos contratantes en principio sólo puede ser limitada por la ley. (AMAZON, 2007, P 200.).

En definitiva, no es que la autonomía contractual sea concebida como un poder ilimitado en virtud del cual las partes puedan arbitrariamente definir la totalidad del contenido negocial, sino que este puede ser restringido pero únicamente por el legislador, con arreglo a lo previsto por los artículos 32 y 40 de la ley 80 de 1993. Así lo puso de relieve la exposición de motivos de la ley 80 de 1993:

"Resulta pertinente reiterar que la libertad contractual que se ha predicado no es absoluta, sino que se encuentra limitada por el propio interés público, en cuanto que el contrato contendrá escogencia del contratante, ya que la administración pública no goza de plena libertad para elegirlo, salvo algunos eventos en razón del proceso de selección que debe cumplirse. También se presentan límites que tienen que ver con la forma en que el Estado compromete su voluntad, es decir, referentes a la competencia. De lo señalado se puede concluir que el postulado de la autonomía no puede regular aquellos campos que pertenecen exclusivamente a la esfera del derecho público, en razón del interés colectivo que los fundamenta. (BENDECK, 1992 p. 23).

2.3.1 Principio de legalidad. El Estado se encuentra sometido a la normatividad jurídica, que se concreta en uno de los principios motores del Estado de derecho, esto es, el principio de legalidad, entendido como la sujeción al orden jurídico 
que irremediablemente recoge la totalidad de las normas, principios y valores que inspiran un sistema jurídico, pues la relación entre la administración pública y los administrados debe ser clara, por tratarse de normas reguladoras de la vida social, para evitar revivir el estilo autocrático de Luis XIV y afianzar cada día el postulado de la Revolución francesa de la despersonalización del poder.

Frente a dicho principio se han dado distintas concepciones clásicas, expuestas por el sistema francés y germánico; el primero, explicaba la ley como voluntad general que determinaba previamente la totalidad de la actuación de los poderes públicos (la nación se manifestaba a través del Parlamento), pues la ley apareció como un instrumento necesario, básico y prevalente que habilitaba el comportamiento de la administración pública, en reemplazo de la voluntad individual de un gobernante; por su parte, en el sistema germánico el príncipe como ente soberano actuaba de manera comprometida con la satisfacción de los intereses generales, logrando un bienestar general con limitaciones en las normas generales. ( SANTOFIMIO. 2004).

En nuestro ordenamiento jurídico, caracterizado como Estado social de derecho sujeto al régimen de la supremacía de la ley, es claro que la actividad de la administración debe estar permanente subordinada a las normas legales principio de legalidad, que en nuestra Constitución Política se encuentra regulado en el artículo 6, así: "Los particulares sólo son responsables ante las autoridades por infringir la Constitución y las leyes. Los servidores públicos lo son por la misma causa y por omisión o extralimitación en el ejercicio de sus funciones”.

La legitimación del acto se obtiene por medio de la autorización legal, a diferencia de los particulares que pueden hacer todo lo que no les esté prohibido expresamente por la Constitución y la ley, mientras que los funcionarios del Estado tan sólo pueden hacer lo que estrictamente les está permitido por ellas. Y es natural que así 
suceda, pues quien está detentando el poder necesita estar legitimado en sus actos, y esto opera por medio de la autorización legal; todo ello como garantía para la sociedad civil, pues es una forma de evitar el abuso del poder por parte de aquellos servidores (AMAZO, 2007. P.189).

Todas las normas que conforman el sistema jurídico deben ser compatibles con nuestra Constitución Política, teniendo como objetivo la coherencia del ordenamiento jurídico y por lo tanto su seguridad y certeza. De tal manera que para comprender un poco más el principio de legalidad en nuestro sistema jurídico, se debe hablar del principio de jerarquía, el cual establece que todo ordenamiento jurídico, y concretamente el administrativo, presenta una estructura jerárquica a la que deben ceñirse todos los órganos del Estado.

En virtud de ello, el principio de legalidad es un elemento central en el ordenamiento jurídico, que establece un marco de actuación de los órganos en donde la ley entra a limitar y obligar a la administración y a los ciudadanos dentro de una relación contractual a aplicar la norma de acuerdo con las circunstancias de cada caso sin que medie un exceso por parte del Estado y de los particulares, ni actuar en aquellas situaciones en las que no está expresamente facultado.

\subsection{LA AUTONOMía de la VOLUNTAd FRENTE AL PRINCIPIO DE LEGALIDAD EN EL CONTRATO ESTATAL.}

En este ambiente de respeto a los acuerdos contractuales y de revisión de los contractos, un sector afirma que la autonomía privada de los contratantes no debe estar limitada, ni siquiera por el principio de legalidad, y que el Estado no debe intervenir en 
las relaciones contractuales. (DE LA PUENTE, 1983, P. 50.); Otro sector afirma que el contrato no debe ser revisado Judicialmente porque alguno de los contratantes dice que se encuentra lesionado por el contrato o porque circunstancias imprevisibles y extraordinarias han generado una alteración en las prestaciones de las partes contratantes, pues cuando las personas deciden contratar lo hacen libremente, como también, en forma libre, determinan el contenido de los contratos, encontrándose, por lo tanto, cada una de ellas en la situación de poder prever las posibles contingencias de un posible incumplimiento por la otra, para lo cual pueden incorporar al contrato instituciones que refuercen su cumplimiento, como podría ser una cláusula penal, multas, mora automática, intereses, entre otros.( MAZEAUD, 1978, P. 130).

Técnicamente, el contrato es el acto jurídico bilateral que mediante el consentimiento (declaración conjunta de las voluntades) de los contratantes crea, regula, modifica o extingue una relación jurídica obligacional de carácter patrimonial. En consecuencia, mediante los contratos, las personas naturales o jurídicas buscan obtener una finalidad que el derecho les permite alcanzar. Por lo tanto, el tráfico patrimonial de bienes y derechos tiene como vehículo más idóneo al contrato, como fruto del libre consentimiento de las partes contratantes, siendo la voluntad de ellas fuente generadora de obligaciones por delegación expresa de la ley. Así, en la celebración de todo contrato estatal existe un límite de buenas costumbres, orden público y cargas, llamados por la doctrina deberes secundarios o accesorios de comportamiento que las partes deben observar para obtener los efectos buscados con la celebración del contrato, entre los cuales se encuentran:

a. Carga de legalidad: es un deber de las partes identificar el tipo negocial que se celebrará y la construcción de un contrato atípico cuando los existentes no logren la finalidad buscada, pues de lo contrario se obtendrán fines distintos o se afectará la celebración o ejecución del contrato. 
b. Carga de claridad: la voluntad de las partes debe ser clara, transparente, que no conlleve aspectos oscuros sujetos a diversas interpretaciones especialmente en los términos de referencia o pliegos de condiciones.

c. Carga de sagacidad y diligencia: la contratación debe estar integrada por una actuación prudente y diligente que evite una responsabilidad sin necesidad. (DÁVILA, 2003, p. 352-353).

Así mismo, varios doctrinantes han expresado que se tiende a confundir el hecho de que la voluntad del contratante haya creado la situación con el hecho de que la voluntad haya creado el vínculo, porque no se trata de crearlo, sino que se está obligado a observarlo por haberlo querido. En segundo lugar, la llamada libertad contractual, referida al poder para obligarse, tiene limitaciones que afectan al contratista y no al poder del contratante para crear un contrato, pues la ley no impide al contratante que respete y cumpla la promesa junto con sus cláusulas, sino lo que limita es el poder para concluir el contrato sin forma o fijación de cláusulas, pretendiendo su cumplimiento. En tercer lugar se habla de una ambigua concepción de fusión de voluntades en el contrato, de unas voluntades fundidas (confusas) en una voluntad que es ley para las partes (creada), porque al hablar de voluntad se entiende que es algo interno, inseparable de la persona, por lo cual es incontrolable y el contrato es algo establecido o expresado en un medio social y controlable (FERRANDIS, 1959,p. 98).

La autonomía de la voluntad en la administración puede entenderse como discrecionalidad, ya que es la expresión de la libertad de determinación de la administración, es decir, podría hacer no meramente aquello que la ley expresamente le autoriza, sino todo aquello que la ley no le prohíbe, entendiéndose como que la administración puede usar en su discrecionalidad todo aquello que la ley no ha regulado. (GORDILLO, 1998.). 
Antes se excluían rotundamente del control judicial, todos los actos administrativos dictados en ejercicio de una potestad discrecional, justamente por saber que el criterio de estos actos no se encuentra en la ley, sino que hace parte de la libertad absoluta de la administración.

La jurisprudencia constitucional ha reconocido que no se conciben la libertad y la autonomía de la voluntad como derechos de carácter absoluto, pues ello es el producto de una filosofía individualista que imperó en los siglos XVIII y XIX, pero que ha sido superada por la concepción moderna del Estado social de derecho que inspira la Carta de 1991 (Sentencia C-641 de 2000). En efecto, su carácter relativo nace de la necesidad de otorgar un tratamiento jurídico a otros derechos amparados en principios que también gozan de amparo constitucional, por lo que surge la necesidad de ponderar principios y derechos en orden a establecer en un contexto determinado a cuáles se otorga primacía en cuanto valores fundantes del Estado social de derecho (Preámbulo y artículos 1 y 2 de la Constitución Política). (AMAZON, 2007, P.201), (Colombia, Ministerio de Gobierno, Nuevo Régimen de Contratación Administrativa, Imprenta Nacional, Bogotá, 1993, pp. 30-31.).

La autonomía de la voluntad entonces, debe seguir rigiendo las relaciones contractuales, en donde se respeten los límites que han enunciado, los diferentes tratadistas que tenemos como referencia pero que no por ello sean instrumentos para borrar o desaparecer lo que las partes han acordado con plena voluntad y conciencia. La preocupación enunciada en los artículos anteriores consiste en determinar si el principio de la autonomía de la voluntad debe ser un principio absoluto e inmutable, o si por el contrario su campo de acción debe estar limitado por el Estado, específicamente, mediante el principio de legalidad, con la finalidad de evitar el abuso en la contratación estatal por parte de uno de los contratantes en perjuicio de la otra parte, abuso que puede ser consecuencia de diversos factores, como la evidente desigualdad económica o 
la información asimétrica en que se encuentran las personas en el momento de contratar. (BALLESTEROS, 1999)

\subsection{LA AUTONOMÍA DE LA VOLUNTAD FRENTE AL CONTRATO ESTATAL}

La Ley 80 de 1993 al regular el contenido del contrato estatal defirió en su artículo 40 a lo previsto por las normas civiles y comerciales, a tiempo que previó que las entidades pueden celebrar los contratos y acuerdos que permitan la autonomía de la voluntad y que se requieran, por supuesto, para el cumplimiento de los fines del Estado. En consonancia con este canon legal, pueden citarse -entre otros- los artículos 13, 23, 28, 32 y 46. Estas previsiones legales entrañan el reconocimiento positivo, como ha reconocido una y otra vez la Corte Constitucional, de la prevalencia de la autonomía de la voluntad para la celebración de contratos por las entidades estatales, como principio nuclear de las relaciones negociales del Estado. Si se recurre al espíritu de la ley 80, para determinar su alcance a partir del elemento histórico (voluntas legislatoris), esto es, de la historia fidedigna de su establecimiento, se tiene que la intención del legislador fue siempre la de reivindicar el citado postulado de la autonomía de la voluntad. Autonomía de la voluntad que había sido reconocida por la jurisprudencia administrativa, mucho antes de su consagración expresa en la ley 80 como "núcleo esencial del negocio jurídico”, en sus diversas manifestaciones. Importa para el asunto sub lite sólo resaltar la concerniente a la libertad negocial, norma medular del régimen de las obligaciones, según la cual las partes no sólo pueden celebrar todos aquellos negocios jurídicos que emerjan de la autonomía de la voluntad, sino pactar también condiciones negociales particulares, conforme al artículo 1602 del CC., ajustando el contrato en cuanto a modo, tiempo y lugar para el cumplimiento de las prestaciones. Por manera que como en el derecho común, la Administración también puede pactar con cierta libertad las cláusulas usuales según su naturaleza, siguiendo las reglas del 
derecho privado, a menos que exista disposición legal en contrario. En definitiva, no es que la autonomía contractual sea concebida como un poder ilimitado en virtud del cual las partes puedan arbitrariamente definir la totalidad del contenido negocial, sino que este puede ser restringido pero únicamente por el legislador, con arreglo a lo previsto por los artículos 32 y 40 de la ley 80 de 1993. Lo dicho da base suficiente para subrayar que cuando los incisos $2^{\circ}$ y $3^{\circ}$ del artículo $6^{\circ}$ del decreto 1436 de 1998 establecen, sin fundamento legal alguno, limitaciones en cuanto al número de intermediarios de seguros que puede tener una entidad estatal, así como restringen el límite temporal de la vinculación del intermediario desbordan con creces el ámbito reducido de la potestad reglamentaria y atentan contra la libertad negocial, como una de las facetas características de la autonomía de la voluntad, que como se indicó tiene su sustento expreso en los artículos 40 y 32 de la ley 80 de 1993, arriba citados. No debe perderse de vista que la potestad reglamentaria que atañe al Presidente de la República como suprema autoridad administrativa está concebida por el ordenamiento constitucional vigente bajo una concepción eminentemente finalística: "para la cumplida ejecución de las leyes" (art. 189.11 CN). Corte Constitucional, sentencias C-154 de 1997, MP Hernando Herrera Vergara; C-230 de 1995, MP Antonio Barrera Carbonell; C-154 de 1996, M.P. Antonio Barrera Carbonell y C-949 de 2001, M.P. Clara Inés Vargas Hernández. Consejo de Estado, Sección Tercera, auto de 24 de marzo de 1994, rad. 9354.

\subsection{LA AUTONOMÍA DE VOLUNTAD REGULADORA DE NORMA}

Entre los socios, se apela al concepto de autonomía para poder generar un tipo de relación de poder donde los socios minoritarios se someten a las pretensiones de quien es el socio capitalista mayoritario. Es así como en este caso, el concepto de autonomía que no está previsto en la ley debe ser legilado para el equilibrio de los poderes dentro de las sociedades SAS y de los contratos societarios, pues el desarrollo de dinámicas de 
toma de decisiones autónomas propuestas por el máximo capitalista, están generando que las relaciones se tornen desiguales y que no haya dentro de la sociedad algunos elementos que entren para regular la formulación del contrato societario. Es decir que el concepto de autonomía tiene unos problemas de interpretación pues lleva a dos caminos, por un lado a la auto-regulación pero por el otro a generar una base conceptual para las relaciones de poder. (Garrigues y Utria Rodríguez, 1977. p. 559).

Es así como se debe tener en cuenta el concepto de autonomía desde su diversidad de ángulos. El primer problema de la idea de autonomía proviene de la ambigüedad del término, porque nos lleva hacia dos terrenos en el derecho que en ocasiones son incompatibles como es el abuso del poder y la auto-regulación. La paradoja de la autonomía, en suma, no ha encontrado todavía una solución satisfactoria. Algunos autores defienden el concepto pero otros no dan con la paradoja que este proceso implica. Es así como el estudio del concepto de autonomía en el contrato societario es un elemento fundamental en el proceso de construcción de las normas y reglas de juego dentro del contrato societario y las sociedades SAS, pues hay mucho elementos de doble valencia que todavía no nos da mucha claridad sobre lo que es el proceso del contrato societario en realidad.

¿Por qué es importante revisar la autonomía en el contrato societario? porque la norma de auto-regulación depende del juicio de uno mismo de la auto regulación que puede tener el sujeto al momento de realizar el contrato. Estos dispositivos nos llevan a revisar las relaciones de poder, pues la autonomía en las relaciones con el contrato societario nos llevan a someter a los socios a la voluntad de los más poderosos, elementos que finalmente son los que combate la legislación. 
Es así, como la autonomía entendida como auto regulación dentro de un proceso de contrato societario debe entrar a ser regulada, sino se presenta este hecho se realizan abusos del poder que finalmente dejen a los socios minoritarios a merced de los que imponen mayor capital. Es una micro - física del poder como lo ha planteado muy bien el filósofo francés Michel Foucault, cuando las relaciones de saber y de poder se conjugan para garantizar la armonía del poder por parte del más poderoso.

En suma la autonomía es el rasgo del proceso de toma de decisiones o establecimiento de formaciones normativas (Habermas; 2002), que a partir de las prácticas sociales se van convirtiendo en un argumento normativo que justifica en ocasiones el uso y el abuso del poder.

\subsection{LA AUTONOMÍA DE VOLUNTAD COMO CAPACIDAD REGULATORIA EN EL CONTRATO SOCIETARIO}

Los pactos o acuerdos societarios, vertidos en los estatutos de cada sociedad, o en los denominados "acuerdos accionistas" constituyen reglas vinculantes relativas, como que los mismos se aplican exclusivamente en la órbita de las relaciones de las partes.

Empero, su aplicabilidad en cada sociedad, frente a cada caso en concreto, está condicionada a la estricta observancia de la jerarquía de las fuentes del derecho comercial, a saber y en estricto orden: La ley comercial imperativa. No solo se refiere a la hipótesis que desarrollan, sino también a la ley civil cuando esta se invoca al tenor del art. 822 del Código de Comercio, según el cual las obligaciones y contratos 
mercantiles se aplican los principios propios de las obligaciones civiles, a menos que haya una ley comercial especial.

En el tema de la autonomía que es el debate que nos interesa, es fundamental porque nos pone a pensar sobre la autorregulación que tienen los sujetos para legislarse con base en el amparo ante la Ley. La autonomía en el contrato societario nos lleva a pensar que la diversidad es posible porque, de acuerdo con la idea de autonomía, las normas no están determinadas por estándares ya dados, sino que dependen, en cambio, de los juicios normativos de los individuos o de las comunidades morales o jurídicas.

Por otra parte, la autonomía es la única idea que puede crear unidad entre las diversas concepciones normativas del Derecho o de la moral, ya que sólo una concepción autónoma de la validez normativa puede lograr la aceptación de agentes que se consideran a sí mismos autónomos, como al menos harán algunos agentes. Es sólo la idea de autonomía, por tanto, la que permite articular una concepción comprehensiva del razonamiento normativo, pieza fundamental en el desarrollo del contrato societario.

En el contrato, Hay que tener en cuenta el art. 4 del Código de Comercio donde se reafirma el carácter privatista del derecho comercial, basado en el postulado de la autonomía de voluntad privada. Es decir que le concede la capacidad regulatoria por encima de la ley supletoria y la costumbre mercantil. Para el caso de las sociedades estos representados en los estatutos (Pinzón 1954. P. 85).

En el ámbito del derecho societario, dicha autonomía de los particulares para auto regularse es cada vez más creciente, y en el derecho contemporáneo se manifiesta 
especialmente en la creciente habilitación legal para que sean los propios asociados quienes configuren la forma o tipo de su sociedad (Espina, 2003). De alguna manera esta tendencia nos ha alcanzado a través de la legislación que dio cabida en Colombia a los Sociedades por Acciones Simplificadas S.A.S., como es de estudio en esta tesis. La capacidad normativa de los actos jurídicos encuentra, no obstante una muralla infranqueable en las disposiciones de la legislación que tienen un carácter imperativo. El poder regulador de los particulares de sus propias causas no puede llegar alterar, modificar o derogar las disposiciones que se informan en razones de orden público, de la tutela del interés general.

Es por ello que el art.4 del Código de Comercio reconoce el poder vinculante de los contratos sólo de preferencia sobre las normas legales supletivas. Por lo que el orden jurídico reclama que las leyes imperativas sean intangibles $e$ inviolables por los particulares, a riesgo de que las convenciones privadas a adolezcan de nulidades que afecte la misma eficacia del acto o del contrato. (Martínez, 2010.) y corroborada en su interpretación la (Sentencia Corte Suprema de justicia sala civil Exp.4798 del 27/3/1998. M.P. José Fernando Ramírez Gómez.)

Se debe distinguir el concepto de contrato que es ley para las partes, es la máxima a través de la cual nuestros códigos lo erigen en fuentes relativa de derecho (art.1062 Código Civil, y art. 4 del Código de Comercio).

2.7.1. La Ley de 1258 de 2008 y la Pluralidad. Con este capítulo trataremos de denunciar en todos los tonos que en la legislación colombiana no existieron las sociedades creadas por una sola persona a pesar que a partir de la aparición de la Ley 1014 de 2006, no pasaba de ser una mentira, porque el legislador jamás la autorizó. (Sentencia Concejo de Estado, fallo del 20 de enero M. P. Rafael Laffón). 
Si bien, es cierto, dicha Ley 1014 de 2006, se limitó a hacer menos compleja la organización de las microempresas que optan por la asociación societaria, particularmente mediante su constitución por documento privado. Pero nunca habilitó la creación de sociedades de una persona, conservando los elementos del contrato societario y en especial el elemento de análisis como es la Pluralidad y el Animus Societattis que constituye la negación misma de la sociedad - contrato, como se le define desde los códigos décimo canónico. Por ello, el art. 22 de la Ley se aplicaba a la nueva sociedad, sin que el legislador del 2006 hubiese tocado un acápite de la definición legal de sociedad que se construye sobre el elemento esencial de la pluralidad de asociados.

Pero otras cosas pensaron los "expertos" gubernamentales en sociedades, que se dieron a la tarea de torcerle innecesariamente el cuello a la ley promoviendo la expedición del Decreto 4463 del 2006, que permitió la constitución de sociedades por unipersonales. Además de ilegal, innecesario. Por el fallo del Consejo de Estado, por el M.P. Rafael Lafont.

Desde la Ley 222 de 1995 existen entre nosotros las empresas unipersonales “E.U." que bien suplen la necesidad de dar curso a la heterodoxa figura de la sociedad unipersonal. En efecto si es posible que un empresario afecte su patrimonio a una determinada empresa mercantil, limitando su responsabilidad y obteniendo el beneficio de la personalidad jurídica, ¿Cuál es la necesidad entonces de insistir en confrontar el concepto de la sociedad como contrato?; de $i$ insistir en una interpretación diferente a la figura del Animus Societattis? y ¿del abuso en la interpretación de la Autonomía del contrato societario?.(Martínez, 2010, p.75). 
Por fortuna la audacia reglamentaria duró poco. La Corte Constitucional intervino en el debate y mediante sentencia C-392 del 2007, señaló sin eufemismo que la Ley 1014 no había cuestionado la naturaleza contractual de las sociedades, por lo que resultaba imperativo que las sociedades debieran contar siempre con el pluralidad de socios, como elemento esencial de su existencia. Con rigor interpretativo dijo la Corte Constitucional que la Ley 1014 del 2006 sólo "hace referencia a las formalidades de la Constitución de sociedades con una persona".

Es decir que la remisión de la Ley en cuestión al régimen de las empresas Unipersonales no se hizo para dar vía jurídica a las sociedades unipersonales, si no para aliviar los formalismos para concebir las pequeñas sociedades y permitir su constitución mediante documento privado. Era suficiente la sentencia de la Corte Constitucional para entender que había decaído el ilegal decreto reglamentario.

Pero en su ciego empeño "modernista" y presentar ante el país supuestos avances significativos por mantener a cualquier costo la inoperante figura de crear sociedades con una persona, los expertos gubernamentales con el eco de algunas cámara de comercio no tuvieron empacho en afirmar que el fallo de Constitucionalidad no había modificado la vigencia del Decreto 4463 del 2006.

Manifestando y justificando buscar un tipo de sociedades más ágiles. En este estado de cosas y en defensa de la legalidad objetiva, no quedaba otra opción que demandar ante el Concejo de Estado el exabrupto reglamentario, que había dado licencia a las sociedades unipersonales, y proceder con la ley 1258 de 2008 que hoy se cuestiona y, como era de esperarse, en celebre fallo del paso 20 de enero con ponencia del Magistrado Rafael Ostau de la Font, el Consejo de Estado declaró la manifiesta 
nulidad del Decreto 4463 del 2006, bajo el imperio de la tesis según la cual "la pluralidad es un requisito esencial del Contrato de Sociedad". De surte que las sociedades unipersonales quedaron solamente en la mente encandilada de los precursores del decreto.

Por lo que puede afirmarse, en derecho, que al carecer uno de sus elementos esenciales nunca nacieron a la vida jurídica las sociedades de un solo socio al amparo del decreto anulado.

Lo más grave de todo es que los gestores de tan irresponsable proceder sabían de su conducta ilegal y se anticiparon a resolver las consecuencias de su aventura reglamentaria.

Por ello se aprovechó el trámite de la Ley 1258 del 2008, que creó las Sociedades por Acciones Simplificadas (S.A.S) para disponer en su artículo 46 que no se podía crear nuevas sociedades unipersonales al amparo de la Ley 1014 del 2006 y que las existentes tenían un plazo de seis meses para asumir la forma de SAS. Lo que reconocieron el error planteado y decidieron aplicar un plan "B" para lograr su cometido.

Con base a esta disposición se ha dicho que la sentencia de nulidad del Concejo de Estado ha quedado "en el plano teórico", con lo cual nos quieren conducir o través por el camino equivocado. 
Porque la Ley 1258 de 2008, no podía, como lo hizo, hablar de las sociedades unipersonales creadas por la Ley 1014. Como ya ha quedado claro según la jurisprudencia de la Corte Constitucional y el Consejo de Estado. Dichas sociedades jamás se pudieron organizar y las que se registraron en la Cámara de Comercio "no tienen existencia legal" de conformidad con el Art. 98 del Código de Comercio. Como corolarío de lo cual si no existieron, mucho menos estaban llamadas a convertirse en SAS.

Se dirá que dicha afirmación es contraria a la Ley 1258 de 2008 . Pero no hay tal. Lo que ocurre es que esa Ley es manifiestamente inconstitucional, por violentar decidida y reflexivamente el principio de la cosa juzgada constitucional. Ya había dicho la Corte Constitucional en le Sentencia C-392 del 2007 que la Ley 1014 del 2006 no creó las sociedades unipersonales, luego no podía la Ley 1258 de 2008, darse la licencia de regularlas, apartándose así en forma grosera del fallo emitido por el máximo tribunal de la jurisdicción constitucional.

Alguien tendrá que responder por este desorden. Las autoridades que transitaron todo este despropósito están llamados a buscar una solución para los empresarios que de buena fe se acogieron a las normas ilegales y que, ahora, se les quiere amparar insensatamente bajo el ropaje de una SAS, sin tener conciencia de que dichas sociedades nunca alcanzaron la declaratoria de inexiquibilidad del artículo 46 de la Ley 1258 de 2008. Porque si ello ocurre, ¿de qué dimensión será el daño causado? (Martínez Neira. 2010.). 


\section{CONCLUSIONES}

Como conclusión del presente trabajo de investigación sobre el análisis del concepto de la pluralidad y la autonomía de la voluntad en el contrato societario, es importante mencionar que su participación en el desarrollo de la legislación, y la sociedad mercantil en Colombia, contribuye para la comunidad estudiantil, los académicos y el sector productivo, la claridad suficiente para saber qué tipo de sociedad y el régimen de responsabilidad recae sobre la sociedad y las relaciones comerciales.

Haciendo hincapié sobre un tema tan controversial como son las llamadas "SAS" que pueden crear sociedades comerciales con una sola persona, violentando los conceptos filosóficos y epistemológicos de la pluralidad de personas y la autonomía de voluntad en los principios rectores de legislación comercial en el contrato de sociedad. Lo que podemos afirmar es que la figura de la unilateralidad puede participar en los mercados y la economía, utilizando un estilo que se regulo en su momento con la ley 222 de 1995, las llamadas E.U.

Refiriéndonos a los resultado arrojados por la cámara de Comercio de Cartagena en las encuesta realizada podemos decir a nivel general que la creciente de S.A.S. en el país, se debe a lo novedoso en el formalismo por ser un documento privado, y 
régimen de responsabilidad pero nuestro estudio arrojo que en un $90 \%$ son creadas por dos socios, lo que atribuye al acuerdo de voluntades entre las partes la figura de la pluralidad y por su puesto a la celebración del contrato societario.

La figura de la pluralidad en los contratos societarios genera más confianza en las relaciones del mercado, son más seguros y lo que se busca en un estado como el colombiano es tener un mercado de capital seguro y un sector empresarial fortalecido con el lema de unidad institucional.

Indudablemente la teoría contractualita clásica, la institucionalidad, la del acto y el negocio jurídico ha embestido nuestro ordenamiento jurídico, con influencia francesa e italiana y se ha considerado que las sociedades comerciales son un contrato, basado en el elemento pluralidad a pesar de estar inmersa hoy en día en nuestro ordenamiento legal la figura de la SAS con la posibilidad de realizar este tipo de sociedad con una persona, a pesar de ser declarada inexequible el decreto 4463 de 2006, que dio vida a esta figura jurídica.

Lo que en su momento uno de los tratadistas más importantes de la década en los temas societarios como es NESTOR HUMBERTO MARTINEZ NEIRA, ha manifestado el adefesio y las galimatías de los creadores de la figura jurídica de las SAS, a éstos no les importó la consecuencia ante la comunidad académica y al grupo de especialistas en el tema societario, y pensaron que sólo podía revolucionar con su teoría modernista una resistencia al concepto pluralidad y abuso de la voluntad privada y además realizando un descalabro a la ley. 
Los estudios sobres el concepto pluralidad han permitido que las partes o socios manifiestes sus acuerdos de voluntades en los estatutos basados en las disposiciones supletivas, y respetando el principio contractuales válidamente celebrados, es decir que reúna los requisitos esenciales de los contratos como son los mencionado en el artículo 98 del código de comercio.

Por último, se puede concluir que los principios de autonomía de la voluntad y legalidad no se oponen, por el contrario, justifican su existencia e importancia en materia contractual, ya que las partes desdibujan la arbitrariedad que se crea alrededor de este tema, porque encuentran una regulación expresa de los distintas situaciones que puedan surgir antes, durante y después de la celebración de un contrato, pero que además tienen la autonomía de regular aspectos en blanco que la ley ha dejado y que por el hecho de ser la manifestación de acuerdo entre ellos es respetada e igualmente se convierte en obligatoria. 


\section{BIBLIOGRAFÍA}

ALARCÓN Rojas, Fernando. La ineficacia de pleno derecho en los negocios jurídicos, Bogotá, Universidad Externado de Colombia, 2011.

ALTERINI, Atilio Aníbal. "Los principios sobre los contratos de Unidroit y las soluciones del derecho común”, en Treinta estudios de derecho privado, Bogotá, Temis y Pontificia Universidad Javeriana, 2011.

AMAZO PARRADO, Diana. Revista Estudios Socio Jurídicos, Bogotá- Colombia, 9(2): 181-203.julio - Diciembre de 2007. Universidad del Rosario.

AMBITO JURIDICO.COM LEGIS, El embeleco de las sociedades unipersonales, escrito por NESTOR HUMBERTO MARTINEZ,

ANGARITA GOMEZ, Jorge. Lecciones de Derecho Civil, editorial Temis, 1998. pg.82. Bogotá.

ARANGO, Rodolfo. ¿Hay respuestas correctas en el derecho?, Bogotá, Uniandes y Siglo del Hombre Editores, 1999.

ARBELAR, Joaquín. Fundamentos de Derecho Comercial y Tributario, Editorial Mc Graw Hill. 2000.

ATIENZA, Manuel y Juan Ruiz Manero. Ilícitos atípicos, Madrid, Trotta, 2006.

ÁVILA, Humberto. Teoría de los principios, Madrid, Marcial Pons, 2011. 
BAENA PINTO, Sergio. "Sociedades Mercantiles de Personas formalidades y Situaciones, segunda edición, Editorial Jurídica Chilena, 1984.

BALLESTEROS, José Antonio Las condiciones generales de los contratos y el principio de autonomía de la voluntad, J. M. Bosch Editor, Barcelona, 1999, p. 20.

BARRERO BUITRAGO, Álvaro. "Manual para el establecimiento de sociedades". Teórico práctico, concordado con el nuevo régimen general de sociedades, Ediciones Librería del Profesional. Bogotá, 1.996.

BECERRA TORO, Rodrigo. El pacto arbitral, disponible en [www.acj.org.co/activ_acad. php?mod=posesion\%20becerra\%20toro].

BECERRRA GARCIA, Julián, Revista Vía Inveniendi et Judicandi - VIEI - 15 Vol.82. Ed. Enero - Junio 2013 - CIFRAVI - Derecho USTA Bogotá D.C. 2013.

BENDECK OLIVELLA, Jorge, exposición de motivos al proyecto de ley No. 149 de 1992 en Gaceta del Congreso No. 75, 23 de septiembre de 1992.

BERNAL GUTIERREZ, Rafael. Artículo: "De la utilidad de la empresas individual de responsabilidad limitada."Tomado de: REYES VILLAMIZAR.

BETANCUR CUARTAS, Jaime, Estatuto General de la Contratación Pública, Biblioteca Jurídica Diké, Medellín, 9ª edición, p. 174 y 175.

BETTI, Emilio. Teoría general del negocio jurídico, Granada, Comares, 2008.

BIANCA, Massimo, Derecho Ccivil 3, El contrato, $2^{\circ}$ ed., trad. Por Fernando Hinestrosa y Edgar Cortes Universidad Externado de Colombia, 2007, ps. 54/55.

BOLDÓ RODA, Carmen. Levantamiento del Velo y Persona Jurídica en el

BOTERO Jorge, Sociedades Comerciales, vol. 18, Cámara de Comercio de Bogotá. Bogotá 1986, p.82, el Dec. 4463 de 2006 lleva su firma como ministro de comercio exterior. 
BRUTAU, Prólogo POLO. Barcelona. Ariel. 1958.

CALVO VIDAL, Isidoro Antonio. La Persona Jurídica Societaria. Ed. Consejo General del Notariado, Madrid (España), 2012. (481 págs.)

CAMARA DE COMERCIO DE BOGOTÁ, Folleto: La Costumbre Mercantil. Impreso por Cedro Impresores Ltda.

CAPILLA RONCERO, Francisco. La Persona Jurídica: Funciones y Disfunciones. Madrid. Tecnos. 1984.

CÁRDENAS; Humberto; GARCÍA Gustavo; HOYOS Ricardo ., Comentarios al estatuto general de contratación de la administración pública, 1.a edición, Librería Jurídica Sánchez R. Ltda., Medellín, 1994, pp. 155-158.).

CASSAGNE, Juan Carlos. El principio de legalidad y el control judicial de la discrecionalidad administrativa, Buenos Aires, Marcial Pons, 2009.

CHABAS, Francoise. "La evolución de la noción de culpa en el derecho francés", en Responsabilidad civil, derecho de seguros y filosofía del derecho, Homenaje a Javier

CHEVAllieR, Jacques. El Estado posmoderno, Oswaldo Pérez (trad.), Bogotá, Universidad

CLAUDIA CONSTANZA (2008). Retención en la fuente. Un sistema anticipado de recaudo de impuestos y sus obligaciones fiscales.

Consejo de Estado, Sala de lo Contencioso Administrativo, Sección Primera.

CONSTANZA (2008). Aspectos Tributarios del Sector Solidario. Editorial Kinesis. 
CONSTANZA Loreth Fajardo-Calderón • Miryam Romero Restrepo • Carlos Andrés Vélez Romero

Constitución Política de Colombia de 1991.

Colombia, Ministerio de Gobierno, Nuevo Régimen de Contratación Administrativa, Imprenta Nacional, Bogotá, 1993, pp. 30-31.

Corte Constitucional. Sentencia C-014 del 20 de enero de 2010, M.P.: Mauricio González Cuervo.

Corte Constitucional. Sentencia C-123 del 22 de febrero de 2006, M.P.: Clara Inés Vargas Hernández.

Corte Constitucional. Sentencia C-378 del 23 de abril de 2008, M.P.: Humberto Sierra Porto.

Corte Constitucional. Sentencia C-388 del 5 de abril de 2000, M.P.: Eduardo Cifuentes Muñoz.

Corte Constitucional. Sentencia C-865 del 7 de septiembre de 2004, M.P.: Rodrigo Escobar Gil.

Corte Suprema de Justicia, Sala de Casación Civil. Sentencia del 2 de agosto de 2001, exp. 6146, M.P.: Carlos Ignacio Jaramillo.

Corte Suprema de Justicia, Sala de Casación Civil. Sentencia del 19 de octubre de 1994, exp. 3972, M.P.: Carlos Esteban Jaramillo Scholss.

Criterio Libre / Año 7 / No. 10 / Bogotá (Colombia) / Enero - Junio 2009 / ISSNISSN 1900-0642 175 
CUBEROS DE LAS CASAS, F. (2011). Sociedades por Acciones Simplificadas (sas). Novedades, aciertos y desaciertos. Bogotá: Universidad Javeriana, Grupo Bancolombia y Grupo Editorial Ibañez.

DÁVILA, Guillermo Luis Régimen jurídico de la contratación estatal. Aproximación crítica a la Ley 80 de 1993, 2.a ed., Legis, Bogotá, 2003, pp. 352-353

DE ANGEL YAGÜEZ, Ricardo. La Doctrina del "Levantamiento del Velo" de la Persona Jurídica en la Jurisprudencia. 4ª Ed. Madrid. Civitas. 1997.

DE CASTRO Y BRAVO, Federico. La Persona Jurídica. Segunda Edición. Reimpresión 1991. Madrid. Civitas, S.A. 1990.

DE CUPIS, Adriano. El daño, Barceona, Bosch, 1975.

Derecho Privado Español. Navarra. Thomson-Aranzadi. 4ªdición. 2006.

DE LA PUENTE, Manuel, Estudios del contrato privado, t. I, Cultural Cuzco Editores, Lima, 1983, p. 50.

DOBSON, Juan I. Interés Societario. Ed. Astral, Argentina, 2010. (472 pags).

DOBSON, Juan M. El Abuso de la Personalidad Jurídica -En el Derecho Privado- $2^{a}$ edición. Buenos Aires. Depalma. 1991.

DOBSON, Juan M. El abuso de la personalidad jurídica, Bueno Aires, Depalma, 1991.

DWORKIN, Ronald. Taking rights seriously, Cambridge, Harvard University Press, 1999. Editorial Kinesis.

EGAS PEÑA Jorge: Derecho Societario. Editorial Edino; Guayaquil, (1992), 
ESPINOSA QUINTERO Leonardo. Teoría General de las Sociedades Comerciales. Universidad Sergio Arboleda Tercera edición. (2008).

Estatuto Tributario vigente de Colombia, Leyes, Decretos, etc. Externado de Colombia, 2011.

FAJARDO CALDERÓN, Constanza Loreth; Díaz Cruz, María Constanza y Cabal Cruz, Claudia Constanza (2008). El Impuesto a las Ventas (IVA) y su efecto fiscal en la contabilidad. Editorial Kinesis.

FERRARA FRANCESCO, Empresarios y sociedades, Madrid, Editorial , Revista de Derecho Privado, Pag. 153.

FERRARA, Francisco, Teoría de las personas jurídicas, Madrid, 1929,p.39.

FERRANDIS, José Comentarios a la obra El contrato de Gino Gorla, t. I, Casa Editorial, Barcelona, 1959, p. 98.

FLÓREZ, Julio "La autonomía de la voluntad y la libertad contractual” En la Revista del Colegio Mayor de Nuestra Señora del Rosario, vol. 31, núm. 303, 1936, p. 205.

FREEMAN, Edward (1995). Administration.

FRISCH, Walter. "Sociedad Mexicana”. Tercera Edición, México D.F.1994.

GAITAN ROZO, Andrés. (La SAS: una nueva alternativa para las empresas de familia), en empresas colombianas: actualidad y perspectiva, Bogotá, superintendencia de sociedades, 2009

GALGANO, Francesco, Derecho comercial, Sociedades, T. II, Temis, Bogotá, 1999, p.2. 
GALGANO, Francesco. Derecho Comercial. Las Sociedades. Vol. II. Bogotá. Temis. 1999.

GAMBOA URIBE, Juan Ignacio. "Elemento subjetivo: la culpa y el dolo en la responsabilidad civil”, en aa.vv. Marcela Castro de Cifuentes (coord.). Derecho de las obligaciones, t. ii, vol. 1, Bogotá, Uniandes y Temis, 2010.

GARCÍA DE RENTERRÍA, Eduardo. Reflexiones sobre la ley y los principios generales del derecho, Madrid, Civitas, 1984.

GARRIGUES, Joaquín. Curso de derecho Mercantil.(Tomo $117^{\circ}$ edición ) Bogotá Colombia. Temis. 1987.

GAVIRIA GUTIERREZ, Enrique, Las sociedades en el nuevo código de comercio, Ed. Temis, 1984.

GÓMEZ ROBAYO, L. (2009). Planeación patrimonial de familias. En Ensayos temas de derecho tributario, cambiario, societario, inversión extranjera, comercio internacional.

GORDILlO, Agustín, Tratado de derecho administrativo, Parte General, 1.a ed., Biblioteca Jurídica Diké, Bogotá, 1998.

GRISOLI, A. Las Sociedades de un solo socio 1976. González Ibarra. Edensa.

GUAL ACOSTA, José Manuel. Cláusulas de exoneración y limitación de responsabilidad civil, Bogotá, Jurídicas Ibáñez, 2008.

HARPER, George. "La responsabilidad del accionista y del funcionario en las sociedades conforme a la jurisprudencia norteamericana", en aa .vv. La despersonalización societaria y el régimen de la responsabilidad, Bogotá, Universidad Javeriana, 2005. 
HENAO, Juan Carlos. El daño, Análisis comparativo de la responsabilidad extracontractual del Estado en derecho colombiano y francés, Bogotá, Universidad Externado de Colombia, 2002.

HINESTROSA F, Fernando. La Representación. $1^{\mathrm{a}}$ edición. Bogotá. Universidad Externado de Colombia. 2008.

HINESTROSA, Fernando. Tratado de las obligaciones, Bogotá, Universidad Externado de Colombia, 2007. Hispanoamericana.

IMRE LAKATOS, La Metodología de los Programas de Investigación Científica: Editorial Alianza Universidad. Madrid .1983.

INSTITUTO ARGENTINO DE DERECHO COMERCIAL. La responsabilidad de los administradores en las sociedades y los concursos. Ed. Legis, Argentina, 2009. (454 págs.)

Instituto Internacional para la Unificación del Derecho Privado, Unidroit .

JARAMILLO, I. (n. d.). La sociedad en comandita como forma de planeación sucesoral. Recuperado de http://www.prietocarrizosa.com/ pc/noticiadetalle.aspx?ID=71

JOSERRAND Louis, Del abuso del derecho y otros ensayos, monografía jurídica $\mathrm{N}^{\circ}$ 24, Bogotá, Ed. Temis, 1999.

JOSSERAND, Louis. Del Abuso de los Derechos y otros Ensayos. Versión de Carlos Valencia Estrada. Bogotá. Temis. Colombia. 1982.

KENNEDY, Duncan. Libertad y restricción en la decisión judicial, Bogotá, Uniandes, Pontificia

La sociedad por acciones simplificada como herramienta de planeación sucesoral 
LEAL PERÉZ, Hildebrando. "Derecho de Sociedades Comerciales", Partes General y Especial, Teórico- práctico. Editorial Leyer. Sexta Edición. Bogotá, D.C., 2006.

Ley 1258 de diciembre 5 de 2008 .

Ley 222 de 1995.

LÓPEZ HERRERA, Edgardo. Teoría general de la responsabilidad civil, Buenos Aires, LexisNexis, 2006.

MARTÍNEZ NEIRA, Néstor Humberto. Cátedra de Derecho Contractual Societario, Buenos Aires, Abeledo Perrot, 2010.

MAZEAUD, Henri, León y Jean, Lecciones de derecho civil, Obligaciones: el contrato, la Promesa unilateral, vol. I, parte segunda, Ediciones Jurídicas Europa-América, Buenos Aires, 1978, p. 130

MAYA MAYA. G. R. (2009). Razones y beneficios para convertirse o transformarse en sas. Bogotá: Biblioteca Jurídica Diké.

MENDOZA RAMIREZ Álvaro, “Antecedentes nacionales de la ley 1258 de 2008; en estudios sobre la sociedad por acciones simplificada, Bogotá, Ed. Universidad Externado de Colombia 2010.

MESSINEO Francesco,(1951) Derecho civil y comercial, trad de Santiago SentissMelendo, Buenos Aires. México: Editorial Prentice Hall

MOLINA NAVARRETE, Cristóbal. Persona Jurídica y Disciplina de los Grupos de Sociedades. Prólogo Francisco Capilla Roncero. Bolonia. Publicaciones del Real Colegio de España. 1995. 
MORALES CASAS, Francisco. “Empresas Unipersonales y Pluripersonales”, Ediciones Jurídicas Radar, Primera Edición, Bogotá, 2000.

MORALES DE SETIÉN Ravina, Carlos. "Estudio preliminar”, en aa .vv. Análisis Económico del Derecho, Bogotá, Siglo del Hombre Editores et al., 2011.

MORENO C. Francisco, Como escribir textos académicos según normas internacionales, Ed. Uninorte.

MORENO C. Francisco, como escribir textos académicos según norma internacionales, Ediciones Uninorte, 2010.

MOSSETTITURRASPE, Jorge. Responsabilidad por daños, T. 1, Parte general, Santa Fe, Rubinzal-Culzoni, 2004.

MUGUILlO, Roberto A. Conflictos Societarios. Ed. Astrea, Argentina, 2009. (504 págs.)

MUIÑO, Orlando M., Derecho societario, Astrea, Buenos Aires. 1997p. 153.

NARVAEZ GARCIA José Ignacio. Teoría General de las Sociedades. (1996).

NARVAEZ GARCIA José Ignacio. Derecho Mercantil Colombiano. Teoría General de las sociedades Vol. III. Novena Edición, Editorial Legis Editores S.A., 2002.

NARVAEZ GARCIA José Ignacio, Narváez Bonnet, Jorge Eduardo; Narváez Bonnet Olga Stella. Derecho de la Empresa. Bogotá. Legis. 2008..

NEME VILLARREAL, Martha Lucía. "Buena fe subjetiva y buena fe objetiva”, en Revista de Derecho Privado, n. ${ }^{\circ}$ 17, Bogotá, Universidad Externado de Colombia, 2009. 
NEME VILLARREAL, Martha Lucía. La buena fe en el derecho romano, Extensión del deber de actuar conforme a buena fe en materia contractual, Bogotá, Universidad Externado de Colombia y Centro di StudiGiuridiciLatinomericaniUniversità "TorVergata", 2010.

Organizaciones y contabilidad.

OSPINA FERNANDEZ Guillermo, Teoría General de los Actos o Negocios Jurídicos, Bogotá 2 Ed. Temis 1983.

PÁJARO MORENO, Nicolás. "El contrato y sus principios orientadores", en Derecho de las obligaciones, t. 1, Bogotá, Uniandes y Temis, 2009.

PALACIO Germán. Pluralismo Jurídico. Bogotá: IDEA/Universidad Nacional, 1993

PAREDES HERNÁNDEZ, Alonso. "Ineficacia del acto jurídico", en Derecho de las obligaciones, t. i, Bogotá, Uniandes y Temis, 2010.

PARUELO, Jorge, Historia de la Epistemología de la Ciencias, Universidad de Buenos Aires. 2003.

PEÑA NOSSA Lisandro, De las Sociedades Comerciales (2011),

PERDOMO Burgos, Álvaro. Fundamentos financieros para sistemas de gestión de la calidad.

PINZÓN GABINO, “Derecho Comercial”, volumen III, Editorial Temis, Bogotá, 1960.

PINZON, Gabino, La empresa unipersonal, en Revista Jurisrevista y Consulta, $\mathrm{N}^{\circ}$ 1,

PINZON, Gabino, Sociedades Comerciales. Volumen1. Teoría General. Editorial Temis 1982. 
POLANÍA TELLO, Nicolás. "Consideraciones sobre el régimen de responsabilidad en la sociedad por acciones simplificada”, en aa.vv., Francisco Reyes Villamizar (coord.). Estudios sobre la sociedad por acciones simplificada, Bogotá, Universidad Externado de Colombia, 2010.

Principios Unidroit sobre los contratos comerciales internacionales, Bogotá, Universidad Externado de Colombia, 2004.

QUIRÓS LIZARAZO, Elkin H. y Bustamante García, Hernán C. (2007). Responsabilidad social.

RAMÍREZ LOZANO, James; Torres Castaño, Ana Gladis y Fajardo Calderón, Constanza Loreth (2008). "Planeación Tributaria para las micro, pequeñas y medianas empresas. MIPYMES". Guía práctica para nuevos y actuales emprendedores de negocios. $2^{a}$ ed. Editorial fussión/creativa.

RECANSENS SICHES, Luis, Filosofía del Derecho, Editorial Hispano América México. 1946.

Rengifo García, Ernesto. “El deber precontractual de información”, en Realidades y tendencias del derecho en el siglo xxi, t. iv, Bogotá, Pontificia Universidad Javeriana y Temis, 2010.

ROJAS ROGER, Carlos .Derecho Comercial a su Alcance, editorial Norma. 1981 .Capitulo 5.

ROMINI SERBATI, Antonio. (1823) Nuevo Ensayo sobre el Origen de las Ideas y la Filosofía del Derecho.

Responsabilidad por violación de la buena fe en la sociedad por acciones simplificada 325

Responsabilidad por violación de la buena fe en la sociedad por acciones simplificada 327 
Responsabilidad por violación de la buena fe en la sociedad por acciones simplificada 329

ResponsabilidadCivil.pdf].

Revista de Derecho Privado N.o 51 - ISSN 1909-7794 - Enero - Junio 2014 Universidad de los Andes - Facultad de Derecho y aduanas (pp. 77 - 109). Bogotá: Lewin \&Wills Abogados.

Revista de Derecho Privado, No. 23, julio - diciembre de 2012, pp. 279 a 329 la, School of Law, Law and Econ. ResearchPaper n. ${ }^{\circ}$ 03-18, disponible en [http://ssrn.com/abstract $=429260]$.

Revista de Derecho Privado, No. 23, julio - diciembre de 2012, pp. 279 a 329

Revista de Derecho Privado, No. 23, julio - diciembre de 2012, pp. 279 a 329

Revista de Derecho Privado, No. 23, julio - diciembre de 2012, pp. 279 a 329

REYES VILLAMIZAR Francisco, Derecho Societario. Tomo I. Bogota D. C. Editorial TEMIS. 2004. Pag. 87-88.

REYES VILLAMIZAR Francisco, La Sociedad por Acciones Simplificadas, segunda edición. (2010).

REYES VILLAMIZAR, F. (2010). sas: la sociedad por acciones simplificada. (2a ed.). Bogotá: Legis.

REYES VILlAMIZAR, F. (2011). Derecho Societario. Tomo I. Bogotá: Temis S. A.

REYES VILLAMIZAR, Francisco (2009). SAS, la Sociedad por Acciones Simplificada. Bogotá: Editorial Legis S.A. 
REYES VILLAMIZAR, Francisco. Derecho societario en Estados Unidos, Introducción comparada, Bogotá, Legis, 2006.

REYES VILLAMIZAR, Francisco. "El nuevo proceso societario", en Ámbito Jurídico, 2011, disponible en [http://www.ambitojuridico.com/BancoConocimiento/N/noti 110314-13/noti-110314-13.asp].

REYES VILLAMIZAR, Francisco. "Responsabilidad de los administradores en la sociedad por acciones simplificada", en Estudios sobre la sociedad por acciones simplificada, Bogotá, Universidad Externado de Colombia, 2010.

REYES VILLAMIZAR, Francisco. Artículo: "La Empresa unipersonal de responsabilidad limitada, una demostración empírica". ". En la revista "Juris Consulta" No. 1 de 1.998. Estudio jurídico y práctico de la empresa unipersonal en Colombia. Publicado por el Colegio de Abogados Comercialitas y la Cámara de Comercio de Bogotá.

REYES VILLAMIZAR, Francisco. Derecho societario, t. i, Bogotá, Temis, 2006.

REYES VILLAMIZAR, Francisco. SAS, La sociedad por acciones simplificada, Bogotá, Legis, 2010.

REYES VILLAMIZAR, Francisco. Sociedades Comerciales en Estados Unidos. Colombia. Doctrina y Ley. Bogotá, 1996.

RIPERT, Georges, Derecho comercial. Sociedades, vol. II, Tea, Buenos Aires, 1954, ps. 16 y ss.

RIPERT, Georges, Tratado Elemental de Derecho comercial. Sociedades, vol. II, Tipografía editora Argentina, Buenos Aires, 1954.

RODRÍGUEZ AZUERO, Sergio. "Responsabilidad civil de los administradores de sociedades", 1998, disponible en [http:/www.rodriguezazuero.com/documentos/

RODRÍGUEZ RODRÍGUEZ, Joaquín, tratado de sociedades mercantiles, t.I, $5^{\circ}$ ed., Porrúa, México, 1977, p.13. 
RODRÍGUEZ, César (coord.). La decisión judicial, el debate Hart-Dworkin, Bogotá, Siglo del Hombre Editores y Universidad de Los Andes, 2008.

ROJAS ROGER, Carlos. Derecho Comercial a su Alcance. Editorial Norma ,1981 pg.38. Capítulo 5.

ROMERO RESTREPO, Myriam; Cabal Cruz, Claudia Constanza y Fajardo Calderón, Constanza Loreth (2007). La contabilidad: soporte de información comercial, tributaria y financiera. Armenia: Editorial Arte Imagen.

ROVIRA, Alfredo. Pactos de Socios. Ed. Astrea, Argentina, 2006. (392 págs.)

SANÍN BERNAL, Ignacio. "El trasiego societario de la colectiva a la sas", en aa.vv. De la responsabilidad civil y comercial, Medellín, Diké et al., 2012.

SANTOFIMIO, Jaime Orlando. Tratado de Derecho Administrativo, t. I. 3.a ed., Universidad Externado de Colombia, Bogotá, 2004.

Scognamiglio, Renato. Contribución a la teoría del negocio jurídico, Leysser León (trad.), Lima, Grijley, 2004.

Sentencia del 20 de enero de 2011, exp. 2008-00136, M.P.: Rafael Ostau de La Font Pianeta.

SERICK, Rudolf, Apariencia y Realidad en las sociedades Mercantiles. El Abuso del Derecho por medio de las Personalidad Jurídica. Trad. PUIG

SILVA TAMAYO, Gustavo E. Desviación de poder y abuso del derecho, Buenos Aires, LexisNexis y AbeledoPerrot, 2006.

Sisk L., Henry y Mario Sverdlik (1979). Administración y Gerencia de Empresas. USA: South-Westewrn Publishing. 
SOLARTE RODRÍGUEZ, Arturo. "La buena fe contractual y los deberes secundarios de conducta", disponible en [www.javeriana.edu.co/juridicas/pub_rev/documents/7Solarteult.pdf].

SUESCÚN Melo, Jorge. Derecho privado. Estudios de derecho civil y comercial contemporáneo, Bogotá, Cámara de Comercio de Bogotá, 1996.

Superintendencia de Sociedades. Concepto Jurídico n. ${ }^{\circ} 220-076480$, del 21 de junio de 2011.

Superintendencia de Sociedades. Oficio 220- 005299 del 9 de febrero de 2005.

Superintendencia de Sociedades. Oficio 220- 012360 del 23 de febrero de 2012.

Superintendencia de Sociedades. Oficio 220- 057533 del 26 de marzo de 2009.

Superintendencia de Sociedades. Oficio 220- 087094 del 2 de agosto de 2009.

TAMAYO JARAMILLO, t. i, Bogotá, Diké et al., 2011.

TAMAYO y TAMAYO, Mario, El proyecto de investigación serie aprender a investigar. 2011

TORRES PEREZ, Francisco José. Régimen Jurídico de las aportaciones sociales en la sociedad cooperativa. Monografía asociada a la revista de derecho de sociedades No. 37, Ed. Aranzadi, España, 2012. (508 págs.)

TRONCOSO, María Isabel. "La obligación de tomar medidas razonables para evitar la extensión del daño", en Revista de Derecho Privado, n. ${ }^{\circ}$ 21, Bogotá, Universidad Externado de Colombia, 2011. 
Universidad Javeriana y Siglo del Hombre Editores, 2005.

VALLESPINOS, Carlos Gustavo, El contrato por adhesión a contratos generales, 1. ${ }^{\text {a }}$ ed., Editorial Universidad, Buenos Aires, 1984, p. 26.)

VANASCO, Carlos Augusto. Sociedades Comerciales parte general. Buenos Aires, Argentina. Editorial Astrea. 2006.

VELÁSQUEZ JARAMILLO, L. G. (2008). Bienes (11 ed.). Medellín: Librería Jurídica Comlibros. 33

VÉLEZ, Fernando. Estudio sobre el Derecho Civil Colombiano, t. vi, París, París-América

VIVANTE cesare, Tratado de Derecho Mercantil, traducción española, Madrid, Edit. Reus. (1932).

Ordenamiento Jurídico Colombiano.

Código de Comercio

Código Civil Colombiano

Ley 1116 de 2006

Ley 222 de 1995

Ley 1258 de 2008

Proyecto de Ley 39 de 2007.

Sentencia Corte Suprema de justicia sala civil Exp.4798 del 27/3/1998. M.P. José Fernando Ramírez Gómez. 